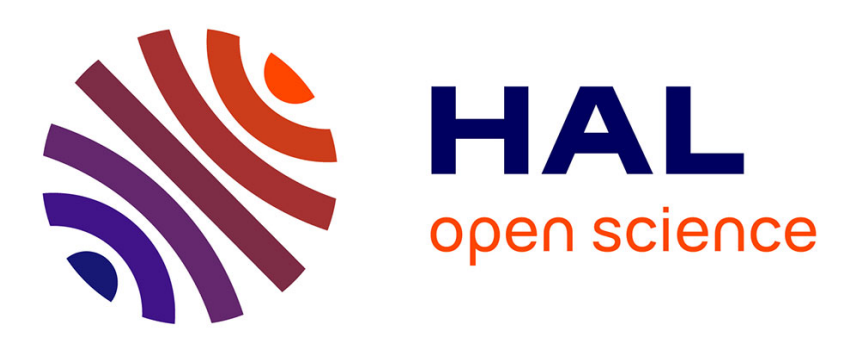

\title{
TTF based donor-pi-acceptor dyads synthesized for NLO applications
}

Awatef Ayadi, Adam Szukalski, Abdelkrim El-Ghayoury, Karolina Haupa, Nabil Zouari, Jaroslaw Mysliwiec, François Kajzar, Bohdan Kulyk, Bouchta Sahraoui

\section{To cite this version:}

Awatef Ayadi, Adam Szukalski, Abdelkrim El-Ghayoury, Karolina Haupa, Nabil Zouari, et al.. TTF based donor-pi-acceptor dyads synthesized for NLO applications. Dyes and Pigments, 2017, 138, pp.255-266. 10.1016/j.dyepig.2016.11.030 . hal-02564425

\section{HAL Id: hal-02564425 \\ https://univ-angers.hal.science/hal-02564425}

Submitted on 7 Sep 2021

HAL is a multi-disciplinary open access archive for the deposit and dissemination of scientific research documents, whether they are published or not. The documents may come from teaching and research institutions in France or abroad, or from public or private research centers.
L'archive ouverte pluridisciplinaire HAL, est destinée au dépôt et à la diffusion de documents scientifiques de niveau recherche, publiés ou non, émanant des établissements d'enseignement et de recherche français ou étrangers, des laboratoires publics ou privés.

\section{(c)(1)}

Distributed under a Creative Commons Attribution| 4.0 International License 


\title{
TTF based donor-pi-acceptor dyads synthesized for NLO Applications
}

\section{Awatef Ayadi $^{\text {a,b }}$, Adam Szukalski ${ }^{c}$, Abdelkrim El-Ghayoury ${ }^{a^{*}}$, Karolina Haupa ${ }^{\text {, }}$, Nabil Zouari ${ }^{\text {, }}$ Jaroslaw Myśliwiec $^{c}$, Francois Kajzar ${ }^{\text {a }}$, Bohdan Kulyk ${ }^{a}$ and Bouchta Sahraoui ${ }^{{ }^{*}}$}

${ }^{a}$ Laboratoire MOLTECH-Anjou, Université d'Angers, UFR Sciences, UMR 6200, CNRS, Bât. K, 2 Bd. Lavoisier, 49045 Angers Cedex, France.

${ }^{b}$ Laboratoire de Physico-chimie de l'état solide, Université de Sfax, Route de Soukra; Km 4; BP: 802, 3038, Sfax, Tunisia.

${ }^{c}$ Faculty of Chemistry, Department of Engineering and Advanced Materials Modelling, Wroclaw University of Technology, Wyb. Wyspianskiego 27, 50-320 Wroclaw, Poland.

${ }^{d}$ Department of Applied Chemistry and Institute of Molecular Science, National Chiao Tung University, 1001, Ta-Hsueh Road, Hsinchu 30010, Taiwan.

Corresponding author: Abdelkrim El-Ghayoury e-mail : abdelkrim.elghayoury@univ-angers.fr Bouchta Sahraoui e-mail : bouchta.sahraoui@univ-angers.fr

\begin{abstract}
Two new TTF-pi-acceptor dyads that contain $p$-nitrophenyl group as acceptor and bis(styryl)benzene system as an efficient $\pi$-conjugated bridge have been synthesized by multistep synthetic procedure and their electrochemical behavior has been studied by cyclic voltammetry (CV). The occurrence of an intramolecular charge transfer (ICT) in these molecules has been evidenced by UV-Visible electronic absorption spectroscopy and these studies were completed by DFT calculations in both gas phase and in solution. The nonlinear optical parameters obtained via SHG and THG measurements are described and indicate that these materials are valuable candidates for the construction of optoelectronic and photonic devices. The Optical Kerr Effect measurements indicate that these materials exhibit a great potential in the field of optical switchers construction, where the material's photoresponse time is a crucial parameter.
\end{abstract}


Keywords: TTF, donor-pi-acceptor, UV-Visible absorption, DFT calculations, nonlinear optics, Optical Kerr Effect.

\section{Introduction}

Push-Pull organic molecules which contain an electron donor (D) and an electron acceptor (A) units that are covalently linked by a $\pi$-conjugated bridging group (D- $\pi$-A systems) exhibiting intramolecular charge transfer (ICT) states have attracted considerable attention because of their possible use as organic optical and electronic functional materials with low energy-gap[1]. Tetrathiafulvalene (TTF) derivatives, which are known to exhibit, in addition to the neutral state, two one-electron reversible oxidation states (i.e. the stable radical cation $\mathrm{TTF}^{+\bullet}$ and dication $\mathrm{TTF}^{2+}$ ) are very useful and versatile $\pi$ electron donating units and play therefore a major role in the preparation of molecular materials designed for various applications. They have been, for example, used as electron donor molecules to prepare (super)conducting crystalline materials[2-5], as redox switches in molecular and supramolecular architectures [6-10], as donor components for photovoltaic devices [11-12] as well as donor moieties in nonlinear optical (NLO) materials [13-16]. For these later materials, numerous studies have shown the important role of both the electron donor and the electron acceptor moieties. Lately, the modulation of the electrooptic coefficient with temperature and pressure has been observed in TTF-derivatized fullerenes [17]. Very recently we have been interested in the use of TTF based ligands, which can also be considered as donor- $\pi$-acceptor systems, in order to tune their electronic properties as well as their nonlinear optical response upon metal complexation. We have therefore shown an increase of the nonlinear optical behavior of orthogonal tetrathiafulvalene (TTF)-based ligands by the complexation with platinum as compared with palladium [18]. In the case of TTF-based iron and ruthenium metal complexes we have observed a switching of the nonlinear absorption character of the systems from Saturable Absorptive to Reverse Saturable Absorptive behavior upon metal complexation [19]. Moreover, we have recently shown an increase of the nonlinear optical response of TTF-based bis-iminopyridine ligand coordinated with zinc(II) metal cation [20]. It is well established that in the field of donor- $\pi$-acceptor molecular structures different design principles are proposed to enhance the nonlinear absorption within a variety of conjugated molecular structures. For this purpose we have selected the TTF moiety as donor part because of the aforementioned properties of these derivatives and nitrophenyl accepting group which has been utilized in many efficient donor-acceptor materials. Also of great importance is the choice of the $\pi$-conjugated spacer which plays a crucial role for the efficient 
electronic communication between the donor and the acceptor parts [21]. It has been shown that the bis-(styryl)benzene (BSB) system acts as an efficient conjugated $\pi$-bridge for NLO materials in which donor (D) and/or acceptor (A) substituents are connected in a symmetrical (D- $\pi$-D, A- $\pi$-A) or asymmetrical (D- $\pi-A)$ arrangements. As the continuation of our research on the preparation of suitable materials for nonlinear optical applications, we report herein on the synthesis, characterization, theoretical calculations and experimental study of nonlinear optical properties of two TTF-based donor-pi-acceptor systems (Scheme 1) which demonstrate high nonlinear optical response.

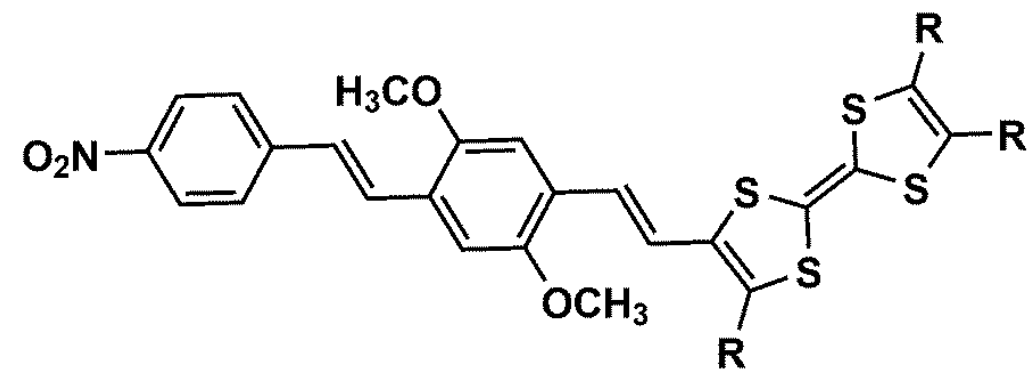

DA-1 $(\mathrm{R}=\mathrm{H})$; DA-2 $\left(\mathrm{R}=\mathrm{CH}_{3}\right)$.

Scheme 1. Chemical structure of the two D- $\pi$-A compounds.

\section{Experimental}

\subsection{Chemicals and characterization techniques}

Commercially available reagents and all solvents for synthesis were of analytical grade and were used without further purification. Reactions were carried out under nitrogen. Nuclear magnetic resonance spectra were recorded on a Bruker $300 \mathrm{MHz}$ spectrometer. The following abbreviations are used to represent the multiplicity of the signals: s (singlet), $d$ (doublet), the spin-spin coupling constants $(\mathrm{J})$ were measured. Infrared spectra were recorded on a Bruker vertex 70 spectrometer, the measurements were recorded in 400 to $4000 \mathrm{~cm}^{-1}$ range. Elemental analyses $(\mathrm{C}, \mathrm{H}$ and $\mathrm{N}$ ) were performed on a Thermo-Scientific Flash 2000 Organic. Mass spectrometry measurements were performed on a Bruker Biflex-III TM which uses 1,8,9-trihydroxyanthracene as matrix. UV-Visible absorption spectra were recorded at room temperature in quartz cuvettes using Perkin Elmer spectrophotometer. Cyclic voltammetry (CV) experiments were performed in a three-electrode cell equipped with a platinum millielectrode as the working electrode, a platinum wire as a counter electrode and a silver wire $\mathrm{Ag} / \mathrm{Ag}+$ used as a reference electrode. The electrolytic media involved a $0.1 \mathrm{~mol} / \mathrm{L}$ solution of $\left(\mathrm{n}-\mathrm{Bu}_{4} \mathrm{~N}\right) \mathrm{PF}_{6}$ in dichloromethane. Melting points were measured with a Melting Point Apparatus SMP3. 


\subsection{Computational details}

The geometry of cis and trans isomers of investigated molecules was performed using the Gaussian09 software [22]. The B3LYP functional with 6-311(d,p) basis set was used for the gas phase calculations. The calculations in DCM (dichloromethane) solution were done using the PCM model (Polarizable Continuum Model) [23] as implemented in the Gaussian09 package [24]. The nature of the optimized geometries at the B3LYP level was checked by vibrational frequency calculations. The vibrational frequencies were calculated for all minima on PES (Potencial Energy Surface) which were confirmed to have zero imaginary frequency. Obtained relative energies include zero point vibrational energy (ZPVE) corrections. The abundances of the found conformers at the room temperature were calculated according to the Boltzmann distribution. The polarizabilities and hyperpolarizabilities were computed using static frequencies. Simulated UV-Vis absorption spectra were obtained by TD-DFT (B3LYP and CAM-B3LYP) method using optimized geometry.

\subsection{NLO experiments}

As the first step of NLO investigations the frequency doubling generation experiments have been conducted. Typical experimental set-up for such purpose has been used as previously described [25]. In our case the fundamental beam of picosecond $\mathrm{Nd}$ : $\mathrm{YVO}_{4}$ laser $(\lambda=1064 \mathrm{~nm})$ was irradiating the samples, which were positioned on the rotational stage. The incident beam was controlled by the set of polarizers, half-wave plates, lenses and electronic system, which synchronized incidental and generated beam. From the reason of structural demands for the $2^{\text {nd }}$ order nonlinear optical effects additional particular procedure was done to prepare samples for this experiment. It was necessary to align molecules in defined direction in order to break centrosymmetry inside volume of the polymeric film. To achieve this alignment of push-pull type molecules we have used corona poling technique $\left(\mathrm{T}=83^{\circ} \mathrm{C}\right.$, heating time: 15 minutes $)$.

\section{Results and discussion}

\subsection{Synthesis}


The synthesis of the starting precursor (a) was carried out according to the previously described procedures [26]. The synthesis of $\mathbf{b}, \mathbf{c}$ and $\mathbf{d}$ (Scheme 2) was inspired from the work published by Fabbrini et al. [21]. TTF aldehydes e [27] and f [28] were prepared according to literature procedures. Thus, the 4-(hydroxymethyl)-2,5-dimethoxybenzaldehyde (a) was reacted with diethyl-4nitrobenzylphosphonate in the presence of $t$-BuOK in dry dimethylfomramide (DMF), under HornerWadsworth-Emmons conditions to give the intermediate b. Subsequent bromination with phosphorus tribromide in tetrahydrofurane solution gave (E)-1-(bromomethyl)-2,5-dimethoxy-4-(4nitrostyryl)benzene $\mathbf{c}$ in $70 \%$ yield. The reaction of triphenylphosphine with $\mathbf{c}$ afforded (E)-(2,5dimethoxy-4-(4nitrostyryl)benzyl) triphenylphosphonium bromide $\mathbf{d}$ which was used in a Wittig reaction with TTF aldehydes (e and f) to afford DA-1 and DA-2 in 57\% and 65\% respectively.<smiles>COc1cc(C=O)cc(OC)c1</smiles>

a

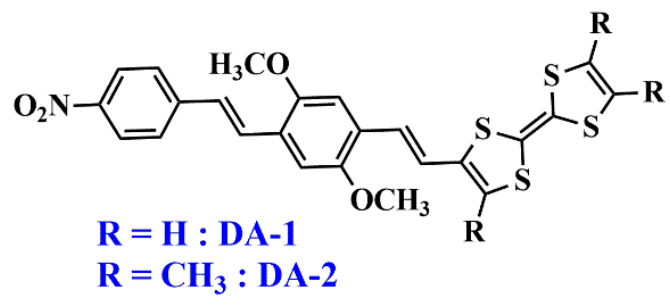

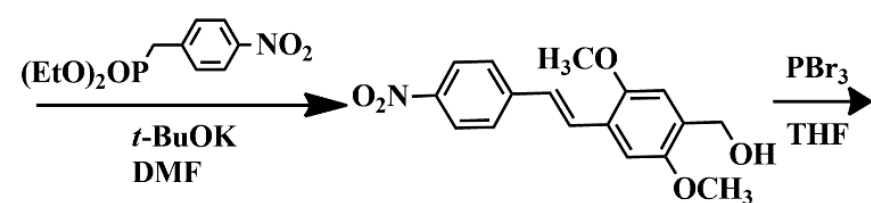

b

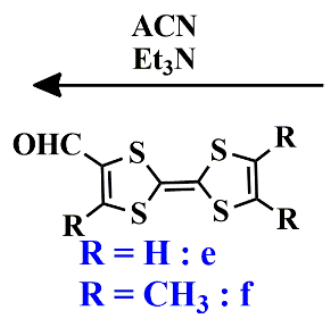

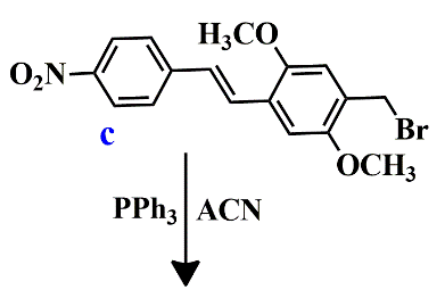

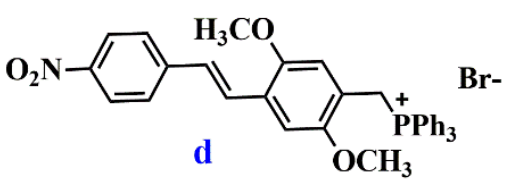

Scheme 2: Synthetic route of compounds DA-1 and DA-2.

\section{Synthesis of (E)-(2,5-dimethoxy-4-(4-nitrostyryl)phenyl)methanol: $\boldsymbol{b}$}

In a three-necked flask under nitrogen, diethyl-4-nitrobenzylphosphonate (348 mg, $1.274 \mathrm{mmol}$ ) was suspended in dry DMF $(10 \mathrm{ml})$, a solution of t-BuOK $(355 \mathrm{mg}, 3.17 \mathrm{mmol})$ was added dropwise. The mixture was stirred for few minutes then, a solution of 4-(hydroxymethyl)-2,5dimethoxybenzaldehyde ( $250 \mathrm{mg}, 1.274 \mathrm{mmol}$ ) was added. The mixture was stirred overnight and 50 $\mathrm{ml}$ of water was then added, the resulting mixture was stirred for additional 10 minutes. The orange solid was filtered and purified by column chromatography (petroleum ether/ ethyl acetate 7/3) to give compound $\mathbf{b}$ as an orange powder in $49 \%$. Mp $130{ }^{\circ} \mathrm{C} ;{ }^{1} \mathrm{H} \mathrm{NMR}\left(300 \mathrm{MHz}, \mathrm{CDCl}_{3}\right) \delta=8.25(\mathrm{~d}, 2 \mathrm{H}$, $\mathrm{J}=8.79 \mathrm{~Hz}), 7.70(\mathrm{~s}, 1 \mathrm{H}), 7.66(\mathrm{~d}, 2 \mathrm{H}, \mathrm{J}=6.83 \mathrm{~Hz}), 7.15(\mathrm{~m}, 2 \mathrm{H}), 6.98(\mathrm{~s}, 1 \mathrm{H}), 4.75(\mathrm{~s}, 2 \mathrm{H}), 3.94(\mathrm{~s}$, $3 \mathrm{H}), 3.93$ (s, 3H), 3.80 (s, 1H). Selected IR bands $\left(\mathrm{cm}^{-1}\right)$ : 3279, 2833, 1628, 1588, 1507, 1462, 1411, 
$1337,1318,1285,1209,1176,1109,1041,968,955,870,829,749,681,669,502$. Anal. calcd for $\mathrm{C}_{17} \mathrm{H}_{17} \mathrm{NO}_{5}$ : C, 64.75; H, 5.43; N, 4.44, found: C, 63.83; H, 5.72; N, 4.04. MALDI-TOF MS calcd: $\mathrm{m} / \mathrm{z}=315.32$ Da. found: $\mathrm{m} / \mathrm{z} 315$.

Synthesis of (E)-1-(bromomethyl)-2,5-dimethoxy-4-(4-nitrostyryl)benzene: $\boldsymbol{c}$

In a three-necked flask under nitrogen, a solution of (E)-(2,5-dimethoxy-4-(4nitrostyryl)phenyl)methanol $(120 \mathrm{mg}, 0.380 \mathrm{mmol})$ in $(10 \mathrm{ml})$ of $\mathrm{THF}$ was cooled to $0^{\circ} \mathrm{C}$. Then, a solution of $\mathrm{PBr}_{3}(122 \mathrm{mg}, 0.452 \mathrm{mmol}$ ) was added dropwise. The mixture was stirred for a further 10 min and 2 hours at room temperature. The solvent was evaporated under vacuum to afford an orange solid. The crude product was purified by column chromatography (petroleum ether/ ethyl acetate 6/4) to afford $\mathbf{c}$ as dark orange powder in $69 \%$. Mp $152{ }^{\circ} \mathrm{C} ;{ }^{1} \mathrm{H} \mathrm{NMR}\left(300 \mathrm{MHz}, \mathrm{CDCl}_{3}\right) \delta=8.24(\mathrm{~d}, 2 \mathrm{H}$, $\mathrm{J}=8.83 \mathrm{~Hz}), 7.68(\mathrm{~d}, 2 \mathrm{H}, \mathrm{J}=8.88 \mathrm{~Hz}), 7.61(\mathrm{~s}, 1 \mathrm{H}), 7.21(\mathrm{~s}, 1 \mathrm{H}), 6.95(\mathrm{~s}, 1 \mathrm{H}), 4.61(\mathrm{~s}, 2 \mathrm{H}), 3.97(\mathrm{~s}$, 3H), 3.92 (s, 3H). Selected IR bands $\left(\mathrm{cm}^{-1}\right)$ : 3045, 2943, 2833, 1724, 1623, 1586, 1511, 1463, 1411, 1332, 1318, 1261, 1213, 1179, 1105, 1041, 975, 955, 866, 848, 829, 748, 697, 686, 659, 555, 501.

Anal. calcd for $\mathrm{C}_{17} \mathrm{H}_{16} \mathrm{NO}_{4} \mathrm{Br}$ : C, 53.99; H, 4.26; N, 3.70, found: C, 53.63; H, 3.94; N, 3.39. MALDITOF MS calcd: $\mathrm{m} / \mathrm{z}=378.2$ Da. found: $\mathrm{m} / \mathrm{z}=378.0[\mathrm{M}]^{+}$.

Synthesis of (E)-(2,5-dimethoxy-4-(4-nitrostyl)benzyl)triphenylphosphonium bromide: $\boldsymbol{d}$

In a three-necked flask under nitrogen, (E)-1-(bromomethyl)-2,5-dimethoxy-4-(4-nitrostyryl)benzene (250 mg, $0.66 \mathrm{mmol}$ ) was suspended in dry ACN (20 ml), a solution of $\mathrm{PPh}_{3}(363 \mathrm{mg}, 1.65 \mathrm{mmol})$ was added dropwise. The mixture was refluxed overnight. After cooling to room temperature, the crude product was filtrated and washed with diethyl ether to yield $\mathbf{d}$ as yellow powder in $90 \%$ yield. $\operatorname{Mp} 245{ }^{\circ} \mathrm{C} ;{ }^{1} \mathrm{H}$ NMR $\left(300 \mathrm{MHz}, \mathrm{DMSO}_{-} \mathrm{d}_{6}\right) \delta=8.23$ (d, 2H, J=8.79Hz), 7.53 (d, 2H, J=5.29 Hz), $7.74(\mathrm{~m}, 16 \mathrm{H}), 7.41(\mathrm{~m}, 1 \mathrm{H}), 7.25(\mathrm{~s}, 1 \mathrm{H}), 6.72(\mathrm{~d}, 1 \mathrm{H}, \mathrm{J}=2.41 \mathrm{~Hz}), 4.99$ (d, 2H, J= 15.26), 3.49 (s, $3 \mathrm{H}), 3.35(\mathrm{~s}, 3 \mathrm{H}) .{ }^{13} \mathrm{C}$ NMR $\left(75 \mathrm{MHz}, \mathrm{DMSO}-\mathrm{d}_{6}\right) \delta=151.3,151.2,150.6,150.5,146.2,144,134.9$, 134, 133.9, 133.3, 133.1, 130, 129.8, 128.9, 128.8, 128.7, 127.8, 127.2, 126.8, 126.7, 125.6, 124.1, 118.7, 117.5, 117, 116.8, 115.8, 115.8, 109.2, 109.1, 55.8, 55.1. Selected IR bands $\left(\mathrm{cm}^{-1}\right): 3372$, 2837, 2773, 2933, 1734, 1587, 1590, 1512, 1468, 1437, 1409, 1294, 1222, 1188, 1106, 1041, 991, 871, 850, 747, 716, 685, 648, 570, 520, 504, 493. Anal. calcd for $\mathrm{C}_{35} \mathrm{H}_{31} \mathrm{NO}_{4} \mathrm{BrP}: \mathrm{C}, 65.63 ; \mathrm{H}, 4.88$; $\mathrm{N}, 2.19$, found: $\mathrm{C}, 64.73 ; \mathrm{H}, 4.84 ; \mathrm{N}, 1.73$. MALDI-TOF $\mathrm{MS}$ for $\mathrm{C}_{35} \mathrm{H}_{31} \mathrm{NO}_{4} \mathrm{P}:$ calcd: $\mathrm{m} / \mathrm{z}=560.19$ Da. found: $\mathrm{m} / \mathrm{z}=560.4[\mathrm{M}]^{+}$. 
To a solution of (E)-(2,5-dimethoxy-4-(4-nitrostyryl)benzyl)triphenylphosphonium bromide (200 mg, $0.321 \mathrm{mmol}$ ) in dry acetonitrile, under nitrogen, a few drops of triethylamine was added. The resulting solution was stirred for $30 \mathrm{~min}$ then a solution of [2,2'-bi(1,3-dithiolylidene)]-4carbaldehyde e $(60.4 \mathrm{mg}, 0.260 \mathrm{mmol})$ in dry acetonitrile was added. The mixture was then refluxed overnight. After cooling to room temperature the desired product was separated by filtration. DA-1 was obtained as a dark powder in $57 \%$ yield, $(76.18 \mathrm{mg}, 0.148 \mathrm{mmol})$. Mp $242{ }^{\circ} \mathrm{C}$; ${ }^{1} \mathrm{H}$ NMR $(300$ $\left.\mathrm{MHz} \mathrm{CDCl}_{3}\right) \delta=8.24(\mathrm{~d}, 2 \mathrm{H}, \mathrm{J}=8.7 \mathrm{~Hz}), 7.69(\mathrm{~d}, 2 \mathrm{H}, \mathrm{J}=8.57 \mathrm{~Hz}), 7.36(\mathrm{~s}, 1 \mathrm{H}), 7.23(\mathrm{~s}, 1 \mathrm{H}), 7.13$ $(\mathrm{m}, 2 \mathrm{H}), 7.01(\mathrm{~d}, 1 \mathrm{H}, \mathrm{J}=5.1 \mathrm{~Hz}), 6.71(\mathrm{~d}, 1 \mathrm{H}, \mathrm{J}=15.7 \mathrm{~Hz}), 6.43(\mathrm{~s}, 1 \mathrm{H}), 6.37(\mathrm{~s}, 2 \mathrm{H}), 3.96(\mathrm{~s}, 3 \mathrm{H})$, 3.95 (s, 3H). ${ }^{13} \mathrm{C}$ NMR $\left(75 \mathrm{MHz}, \mathrm{CDCl}_{3}\right) \delta=151.8,151.6,127.8,126.9,126.8,126.7,124.1,121.7$, 120.3, 119.1, 118.7, 109.5, 109.4, 109.3, 56.2. Selected IR bands $\left(\mathrm{cm}^{-1}\right): 2828,1619,1581,1505$, 1330, 1202, 1043, 642, 502. Anal. calcd for $\mathrm{C}_{24} \mathrm{H}_{19} \mathrm{NO}_{4} \mathrm{~S}_{4}: \mathrm{C}, 56.12 ; \mathrm{H}, 3.73 ; \mathrm{N}, 2.73$, found: C, 55.40; H, 3.65; N, 2.85. MALDI-TOF MS calcd: $\mathrm{m} / \mathrm{z}=513.01 \mathrm{Da}$. found: $\mathrm{m} / \mathrm{z}=513.3[\mathrm{M}]^{+}$. HRMS (M): for $\mathrm{C}_{24} \mathrm{H}_{19} \mathrm{NO}_{4} \mathrm{~S}_{4}:=513.0197$. Found 513.0191.

Synthesis of 4-((E)-2,5-dimethoxy-4-((E)-4-nitrostyryl)styryl)-4',5,5'-trimethyl-2,2'-bi(1,3dithiolylidene): $\boldsymbol{D A}-\mathbf{2}$

This compound was prepared by following the same procedure as for compound DA-1, using 4',5,5'trimethyl-[2,2'-bi(1,3-dithiolylidene)]-4-carbaldehyde f. Yield (65\%); mp $265{ }^{\circ} \mathrm{C} ;{ }^{1} \mathrm{H}$ NMR (300 MHz, DMSO-d $\left.{ }_{6}\right) \delta=8.25(\mathrm{~d}, 2 \mathrm{H}, \mathrm{J}=8.66 \mathrm{~Hz}), 7.85(\mathrm{~d}, 2 \mathrm{H}, \mathrm{J}=8.94 \mathrm{~Hz}), 7.59(\mathrm{q}, 2 \mathrm{H}, \mathrm{J}=16.9 \mathrm{~Hz})$, 7.39 (s, 2H), 7.33 (d, 1H, J= 16 Hz), 6.59 (d, 1H, J= $15.7 \mathrm{~Hz}), 3.93$ (s, 3H), 3.92 (s, 3H), 2.29 (s, 3H), 1.98 (s, 6H). Selected IR bands $\left(\mathrm{cm}^{-1}\right): 2909,1624,1585,1503,1332,1213,1038,632$, 503. Anal. calcd for $\mathrm{C}_{27} \mathrm{H}_{25} \mathrm{NO}_{4} \mathrm{~S}_{4}$ : C, 58.35; H, 4.53; N, 2.52, found: C, 58.04; H, 4.53; N, 2.52. MALDI-TOF MS calcd: $\mathrm{m} / \mathrm{z}=555.06$ Da. found: $\mathrm{m} / \mathrm{z}=555.4[\mathrm{M}]^{+}$. HR-MS $(\mathrm{M})$ : for $\mathrm{C}_{35} \mathrm{H}_{31} \mathrm{NO}_{4} \mathrm{BrP}:=555.0666$. Found 555.0654.

\subsection{UV-Visible absorption spectroscopy}

The UV-Visible absorption spectra of compounds DA-1 and DA-2 were recorded in dichloromethane solution with $\mathrm{C}=4 \times 10^{-5} \mathrm{M}$ and $\mathrm{C}=4.5 \times 10^{-5} \mathrm{M}$, respectively, at room temperature (Figure 1). Both compounds exhibit tow strong electronic absorption bands at 331 and $422 \mathrm{~nm}$ for DA-1 and 337 and $420 \mathrm{~nm}$ for DA-2, which are assigned to the $\pi \rightarrow \pi^{*}$ and $\mathrm{n} \rightarrow \pi^{*}$ transitions resulting from the different units of the two compounds (TTF moiety, phenyl ring and the dimethoxybenzene group). This behavior is similar to that observed for the corresponding nitrosubstituted $p$-phenylene vinylene oligomer [29]. In addition a shoulder is observed for both 
compounds around $500 \mathrm{~nm}$ which might be assigned to an intramolecular charge transfer (ICT) between the TTF moiety and the p-nitrophenyl unit.

(a)

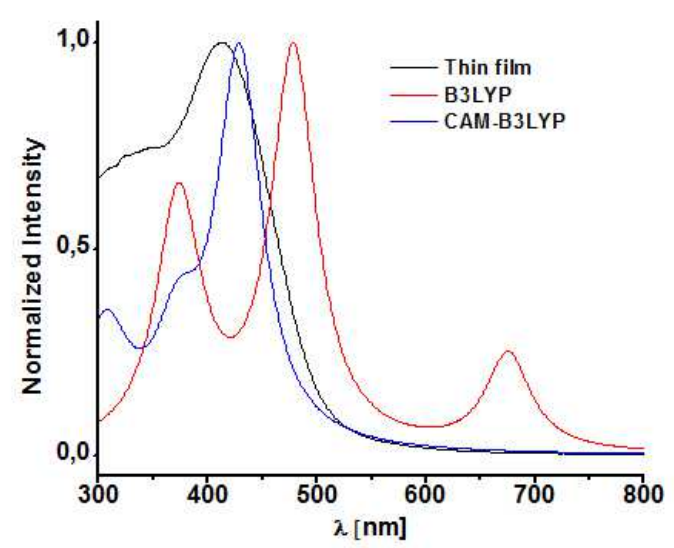

(c)

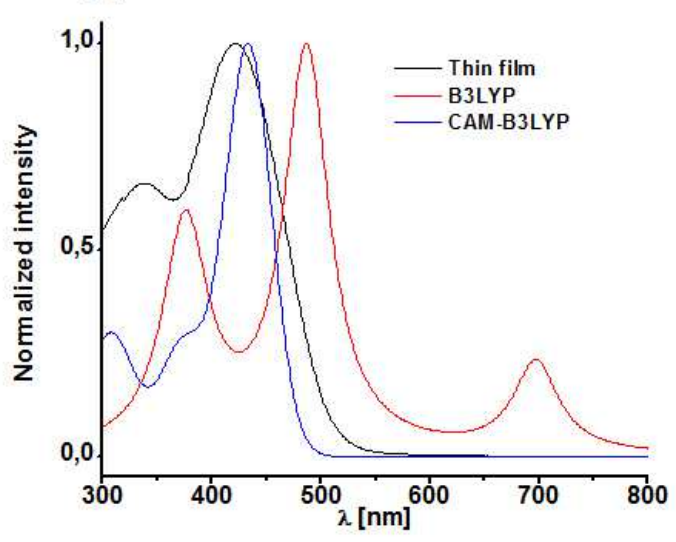

(b)

DA-1

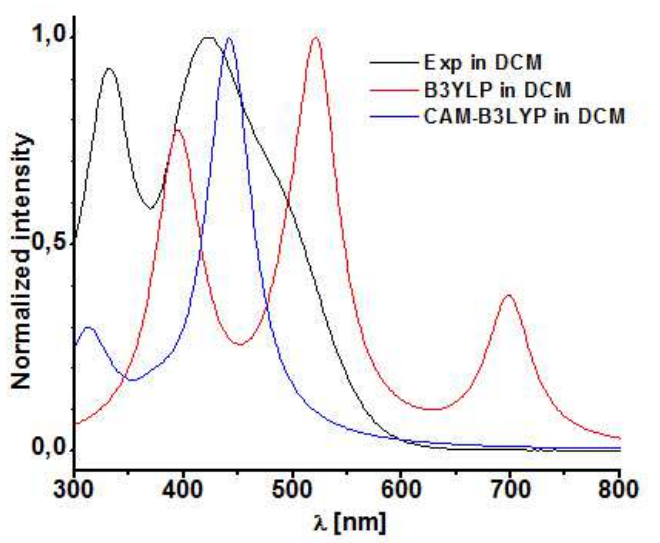

(d)

DA-2

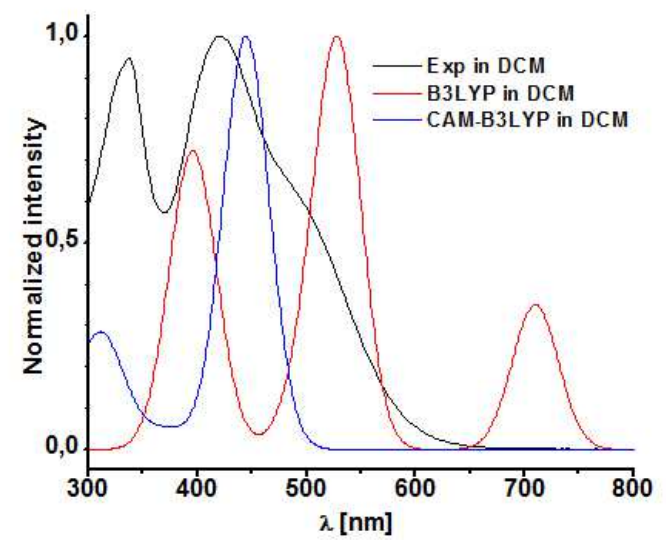

Figure 1. Experimental and theoretical absorption spectra of DA-1 thin film (a), DA-1 in DCM solution (b), DA-2 thin film (c) and DA-2 in DCM solution (d) at B3LYP and CAM-B3LYP/6$311(d, p)$ level of theory.

\subsection{Cyclic voltametry}

The electrochemical behavior of the two compounds DA-1 and DA-2 was examined by cyclic voltammetry (CV) (Figure 2). This measurement shows the usual two reversible one-electron oxidations of the TTF unit, which correspond to the successive formation of a radical cation at 0.35 and $0.28 \mathrm{~V}$ vs $\mathrm{Ag} / \mathrm{Ag}^{+}$and a dication at 0.84 and $0.75 \mathrm{~V}$ vs Ag/ $\mathrm{Ag}^{+}$for DA-1 and DA-2, respectively. Note that $E_{0 x 1}$ of DA-1 is anodically shifted when compared with $E_{0 x 1}$ of DA-2 because of the positive inductive effect of the trimethyl groups in DA-2. 


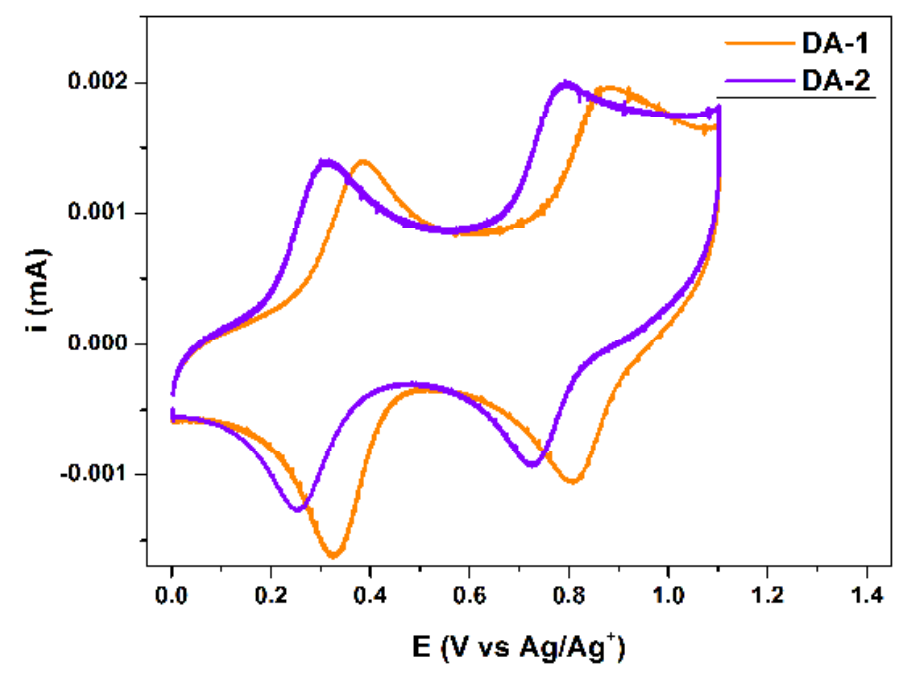

Figure 2: Cyclic voltammograms of compounds DA-1 and DA-2 $\left(\mathrm{C}_{\mathbf{1}}=4 \times 10^{-5} \mathrm{M}, \mathrm{C}_{\mathbf{2}}=4.5 \times 10^{-5}\right.$ $\mathrm{M})$ in $\mathrm{CH}_{2} \mathrm{Cl}_{2}$ at $100 \mathrm{mV} \cdot \mathrm{s}^{-1}$ on a glassy carbon electrode with $n-\mathrm{Bu}_{4} \mathrm{NPF}_{6}(0.1 \mathrm{M})$.

\section{Theoretical calculations}

\subsection{Geometry optimization}

The optimized structures with selected geometry parameters of the most stable cis and trans isomers for DA-1 and DA-2 are presented in Figure 3 (a) and (b), respectively. The relative energies, Gibbs free enthalpies and abundance at room temperature of these minima are collected in Table 1. The PES (Potential Energy Surface) is very flat and the number of local minima is large. It is connected with $-\mathrm{OCH}_{3}$ and $-\mathrm{CH}_{3}$ rotation possibility. We present only the lowest in energy minima for cis and trans isomers. As one can see the most stable forms of both compounds are trans-trans (marked as tt) isomers and only $\mathrm{t}-\mathrm{t}$ forms have contribution to population at $298 \mathrm{~K}$. The structures obtained for both compounds are similar and the t-t isomers are almostplanar. The t-c conformers are 21.9 and $22.3 \mathrm{~kJ} /$ molhigher in energy for DA-1 and DA-2 respectively and they show bended structure. It means that cis-trans isomerization is connected with strong structural reorganization in space. The c-t isomers are relatively close in energy to t-c forms $(24.1$ and $24.3 \mathrm{~kJ} / \mathrm{mol}$ for DA-1 and DA-2 respectively). The cis-cis isomers are much higher in energy (64.3 and $64.6 \mathrm{~kJ} / \mathrm{mol})$.

Table 1. The calculated relative energies, Gibbs free enthalpies, abundance in $298 \mathrm{~K}$ and the $\Delta \mathrm{E}^{\mathrm{HOMO}-\mathrm{LUMO}}$ for DA-1 and DA-2 conformers. B3LYP/6-311(d,p). 


\begin{tabular}{lllll}
\multicolumn{5}{c}{ ACCEPTED MANUSCRIPT } \\
\hline conformer & $\Delta \mathrm{E}(\mathrm{kJ} / \mathrm{mol})$ & $\Delta \mathrm{G}^{298 \mathrm{~K}}(\mathrm{~kJ} / \mathrm{mol})$ & Abundance $(\%)$ & $\Delta \mathrm{E}^{\mathrm{HOMO}-\mathrm{LUMO}}(\mathrm{eV})$ \\
\hline DA-1 t-t & 0.0 & 0.0 & $100 \%$ & 2.078 \\
DA-1 t-c & 21.9 & 23.5 & $0 \%$ & 2.091 \\
DA-1 c-t & 24.1 & 26.0 & $0 \%$ & 2.159 \\
DA-1 c-c & 64.3 & 65.0 & $0 \%$ & 2.163 \\
DA-2 t-t & 0.0 & 0.0 & $100 \%$ & 2.019 \\
DA-2 t-c & 22.3 & 26.3 & $0 \%$ & 2.027 \\
DA-2 c-t & 24.3 & 28.4 & $0 \%$ & 2.070 \\
DA-2 c-c & 64.6 & 65.4 & $0 \%$ & 2.068 \\
\hline
\end{tabular}

(a)
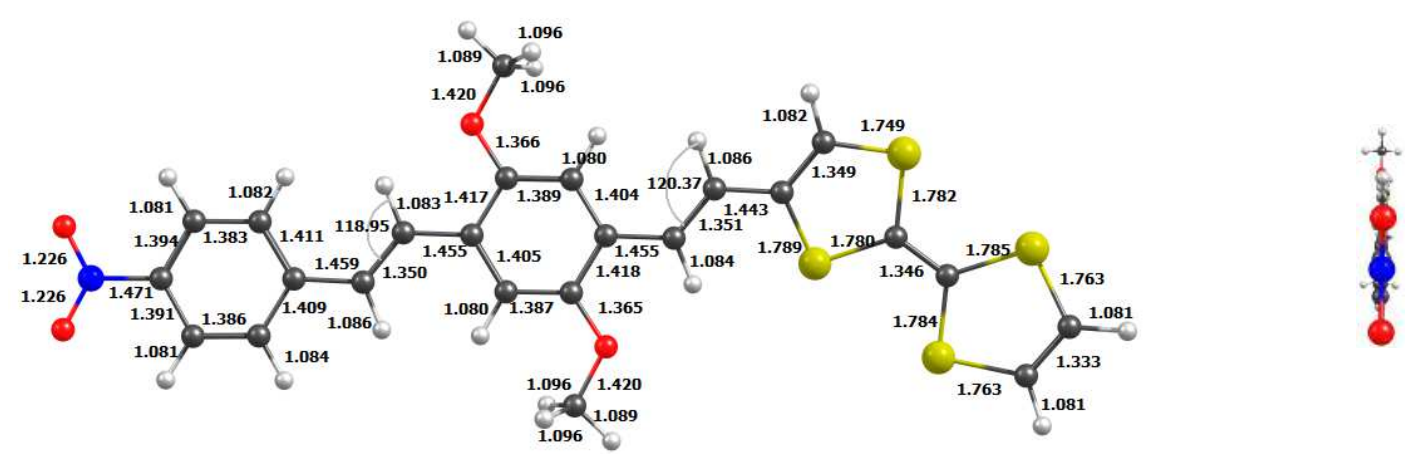

DA-1 t-t

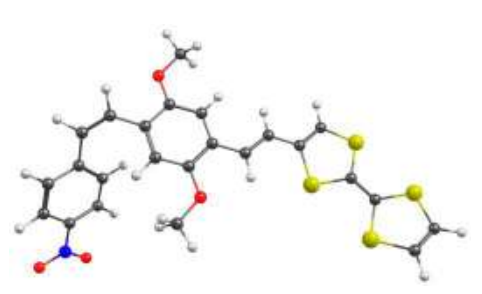

DA-1 t-c

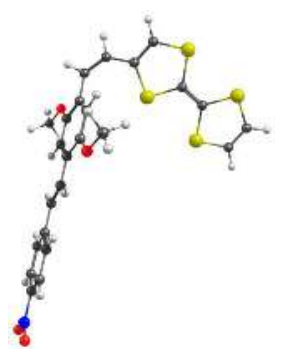

DA-1 c-t

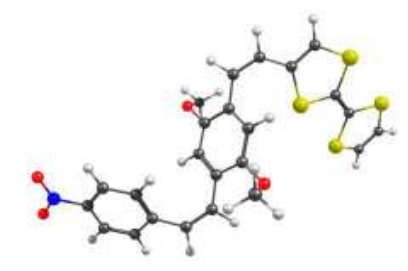

DA-1 c-c

(b) 


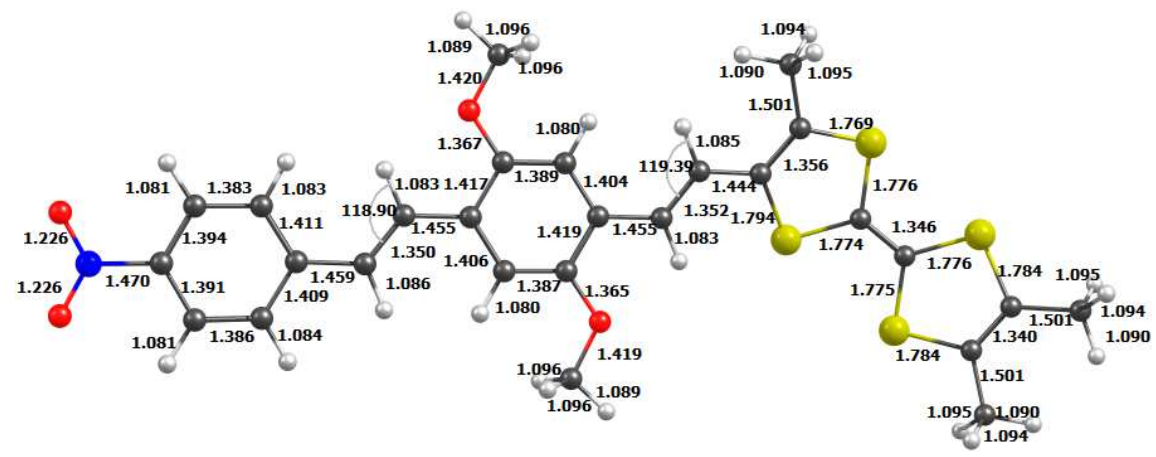

DA-2 t-t

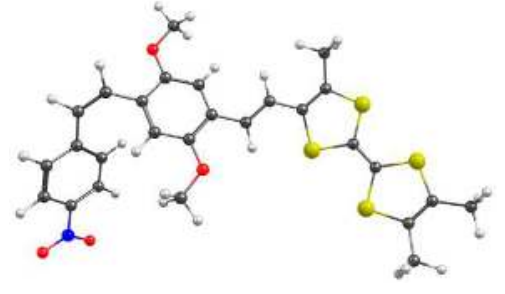

DA-2 t-c

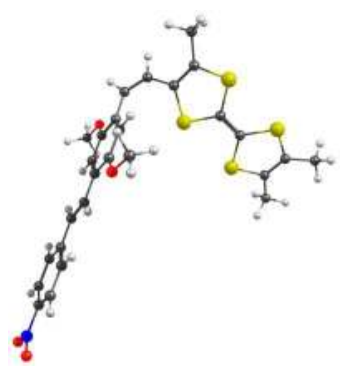

DA-2 c-t

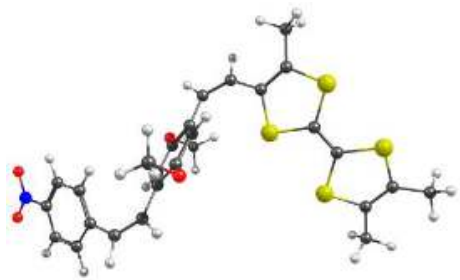

DA-2 c-c

Figure 3. Optimized molecular structures of DA-1 (a) and DA-2 (b) conformers with selected geometry parameters. DFT/B3LYP/6-311(d,p). Atom colors labeling: C - dark gray, H - light gray, $\mathrm{S}$ - yellow, $\mathrm{N}$ - blue, $\mathrm{O}$ - red.

\subsection{Molecular orbitals}

The computed frontier Molecular Orbitals (MO) are rendered in Figure 4. In both compounds the highest occupied molecular orbital (HOMO) is delocalized over electron rich tetrathiafulvalene (TTF) system. In the case of LUMO (lowest unoccupied molecular orbital), one can see that it is delocalized over the $\pi$-conjugated spacer and the accepting $p$-nitrophenyl unit with almost no contribution from electron donating TTF group. The HOMO-LUMO energy gap is relatively low and similar for both compounds and it equals 2.08 and $2.02 \mathrm{eV}$ for DA-1 and DA-2, respectively. The $\Delta \mathrm{E}^{\mathrm{HOMO}-\mathrm{LUMO}}$ for the other conformers are given in Table 2. The HOMO $\rightarrow$ LUMO transition implies an electron density transfer. Moreover, the HOMO-LUMO gap which is relatively low can explain the origin of observed shoulder band in experimental UV-Vis spectra. It indicates that the intramolecular charge transfer (ICT) between the TTF donor and $p$-nitrophenyl acceptor fragment can be responsible for the observed shape of the spectra. 
DA-1 t-t
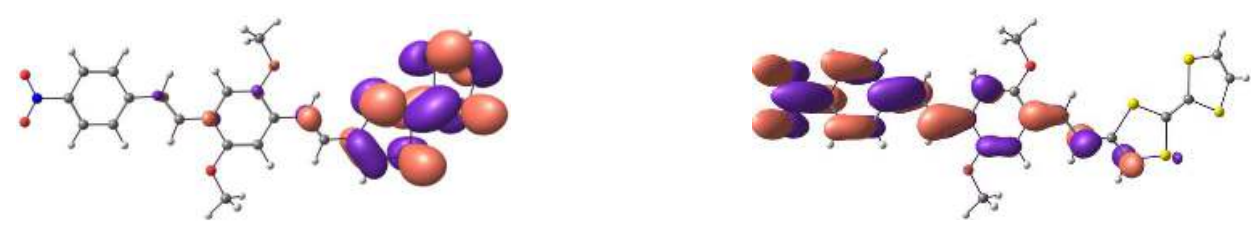

DA-2 t-t
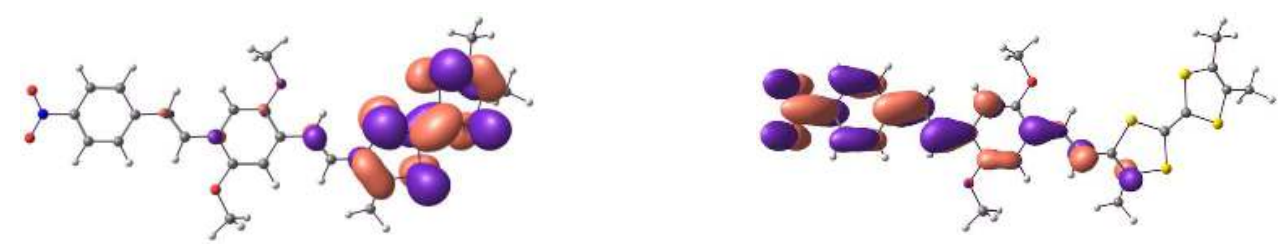

Figure 4. The contour plots (isodensity $=0.02 \mathrm{au}$ ) of HOMO and LUMO of the DA-1 and DA-2 t-t isomers (B3LYP/6-311(d,p) level of theory).

\subsection{Computed UV-Visible absorption spectra}

The vertical excitations energies were calculated using Time Dependent DFT (TD-DFT) [30] in order to characterize the nature of the electronic transitions and assignment of the observed bands in UVVisible absorption spectra. Because of some limitations of TD-DTF B3LYP method and high contribution of charge-transfer transitions the calculations have been also carried out by CAMB3LYP method [31]. Obtained theoretical and experimental results are given in Table 3 and the experimental and simulated spectra are shown in Figure 1.

Table 2. $\lambda_{\text {calc }}$ at B3LYP/6-311(d,p) and CAM-B3LYP/6-311(d,p) (vacuum and DCM solution) and $\lambda_{\exp }$ (thin film and DCM solution) level of theory with assignment of low electronic singlet excitations of DA-1 and DA-2 t-t isomers.

\begin{tabular}{|c|c|c|c|c|c|c|}
\hline & \multicolumn{3}{|c|}{ Absorption wavelength [nm] } & \multicolumn{2}{|c|}{ Oscillator strength } & \multirow[t]{2}{*}{ Transitions (\% weight) } \\
\hline & \multicolumn{2}{|l|}{ Vacuum } & \multirow{2}{*}{$\begin{array}{l}\text { Thin } \\
\text { film }\end{array}$} & \multirow[b]{2}{*}{ B3LYP } & \multirow[b]{2}{*}{$\begin{array}{l}\text { CAM- } \\
\text { B3LYP }\end{array}$} & \\
\hline & B3LYP & $\begin{array}{l}\text { CAM- } \\
\text { B3LYP }\end{array}$ & & & & B3LYP \\
\hline & $\lambda_{\text {calc }}$ & $\lambda_{\text {calc }}$ & $\lambda_{\exp }$ & & & \\
\hline \multirow{7}{*}{$\begin{array}{l}\text { DA-1 t- } \\
\text { t }\end{array}$} & 676 & & & 0.2638 & & $\mathrm{H} \rightarrow \mathrm{L}(98 \%)$ \\
\hline & 486 & & & 0.0124 & & $\mathrm{H}-1 \rightarrow \mathrm{L}(94 \%) \mathrm{H} \rightarrow \mathrm{L}+1(2 \%)$ \\
\hline & 478 & 429 & & 1.0728 & 1.4270 & $\mathrm{H}-1 \rightarrow \mathrm{L}(96 \%) \mathrm{H} \rightarrow \mathrm{L}+1(2 \%)$ \\
\hline & 445 & 386 & & 0.0006 & 0.0006 & $\mathrm{H} \rightarrow \mathrm{L}+1(95 \%) \mathrm{H} \rightarrow \mathrm{L}+2(3 \%)$ \\
\hline & 382 & 372 & & 0.0235 & 0.3530 & $\mathrm{H}-2 \rightarrow \mathrm{L}(69 \%) \mathrm{H}-1 \rightarrow \mathrm{L}+1(25 \%)$ \\
\hline & 373 & 316 & & 0.6642 & 0.0211 & $\mathrm{H}-3 \rightarrow \mathrm{L}(15 \%) \mathrm{H}-2 \rightarrow \mathrm{L}(21 \%)$ \\
\hline & & & & & & $\mathrm{H}-1 \rightarrow \mathrm{L}+1(61 \%)$ \\
\hline
\end{tabular}


307

300

DA-2 t- 697

$\mathbf{t}$

\begin{tabular}{|c|c|c|c|c|c|c|}
\hline & 494 & & 0.0200 & & $\mathrm{H} \rightarrow \mathrm{L}+1(94 \%)$ & \\
\hline & 487 & 433 & 1.0781 & 1.4169 & $\mathrm{H}-1 \rightarrow \mathrm{L}(97 \%)$ & \\
\hline & 450 & 388 & 0.0011 & 0.0019 & $\mathrm{H} \rightarrow \mathrm{L}+2(95 \%) \mathrm{H} \rightarrow \mathrm{L}+3(2 \%)$ & \\
\hline & 391 & 373 & 0.0094 & 0.3832 & $\begin{array}{l}\mathrm{H}-3 \rightarrow \mathrm{L} \quad(4 \%) \quad \mathrm{H}-2 \rightarrow \mathrm{L} \quad(79 \%) \\
(13 \%)\end{array}$ & $\mathrm{H}-1 \rightarrow \mathrm{L}+1$ \\
\hline & 376 & 318 & 0.6137 & 0.0081 & $\begin{array}{l}\mathrm{H}-3 \rightarrow \mathrm{L} \quad(15 \%) \quad \mathrm{H}-2 \rightarrow \mathrm{L} \quad(7 \%) \\
(74 \%)\end{array}$ & $\mathrm{H}-1 \rightarrow \mathrm{L}+1$ \\
\hline & & 308 & & 0.3783 & & \\
\hline & & 297 & & 0.0436 & & \\
\hline & $\mathrm{DCM} / \mathrm{PC}$ & DCM & & & & \\
\hline & B3LYP & $\begin{array}{l}\text { CAM- } \\
\text { B3LYP }\end{array}$ & B3LYP & $\begin{array}{l}\text { CAM- } \\
\text { B3LYP }\end{array}$ & B3LYP & \\
\hline & $\lambda_{\text {calc }}$ & $\lambda_{\text {calc }}$ & & & & \\
\hline DA-1 t- & 698 & & 0.3566 & & $\mathrm{H} \rightarrow \mathrm{L}(98 \%)$ & \\
\hline $\mathbf{t}$ & & & & & & \\
\hline & 522 & 442 & 0.9155 & 1.8300 & $\mathrm{H}-1 \rightarrow \mathrm{L}(99 \%)$ & \\
\hline & 496 & 380 & 0.1232 & 0.0009 & $\mathrm{H} \rightarrow \mathrm{L}+1(96 \%)$ & \\
\hline & 438 & 374 & 0.0004 & 0.0823 & $\mathrm{H} \rightarrow \mathrm{L}+2(92 \%) \mathrm{H} \rightarrow \mathrm{L}+3(5 \%)$ & \\
\hline & 402 & 327 & 0.1356 & 0.0257 & $\mathrm{H}-2 \rightarrow \mathrm{L}(88 \%) \mathrm{H}-1 \rightarrow \mathrm{L}+1(7 \%)$ & \\
\hline & 393 & 312 & 0.6202 & 0.4165 & $\begin{array}{l}\mathrm{H}-3 \rightarrow \mathrm{L} \quad(8 \%) \quad \mathrm{H}-2 \rightarrow \mathrm{L} \quad(6 \%) \\
(83 \%)\end{array}$ & $\mathrm{H}-1 \rightarrow \mathrm{L}+1$ \\
\hline & & 300 & & 0.0526 & & \\
\hline DA-2 t- & 710 & & 0.3420 & & $\mathrm{H} \rightarrow \mathrm{L}(99 \%)$ & \\
\hline $\mathbf{t}$ & & & & & & \\
\hline & 529 & 444 & 0.9361 & 1.8361 & $\mathrm{H}-1 \rightarrow \mathrm{L}(99 \%)$ & \\
\hline & 498 & 383 & 0.1186 & 0.0018 & $\mathrm{H}+1 \rightarrow \mathrm{L}+1(96 \%)$ & \\
\hline & 443 & 372 & 0.0003 & 0.0846 & $\mathrm{H} \rightarrow \mathrm{L}+2(95 \%) \mathrm{H} \rightarrow \mathrm{L}+3(5 \%)$ & \\
\hline & 409 & 327 & 0.0657 & 0.0175 & $\begin{array}{l}\mathrm{H}-3 \rightarrow \mathrm{L} \quad(4 \%) \quad \mathrm{H}-2 \rightarrow \mathrm{L} \quad(88 \%) \\
(5 \%)\end{array}$ & $\mathrm{H}-1 \rightarrow \mathrm{L}+1$ \\
\hline & 395 & 313 & 0.6547 & 0.4271 & $\begin{array}{l}\mathrm{H}-3 \rightarrow \mathrm{L} \quad(11 \%) \quad \mathrm{H}-2 \rightarrow \mathrm{L} \quad(3 \%) \\
(84 \%)\end{array}$ & $\mathrm{H}-1 \rightarrow \mathrm{L}+1$ \\
\hline & & 297 & & 0.1051 & & \\
\hline
\end{tabular}

As it was observed in the case of the Azo-based iminopyridine ligands [32] the calculated wavelengths of low electronic state transitions at CAM-B3LYP level for the dyads DA-1 and DA-2 match better to experimental ones relatively to B3LYP. On the other hand the calculated oscillator 
strength is reproduced better in B3LYP calculations. In all spectra the most intensive transition corresponds to $\mathrm{H}-1 \rightarrow \mathrm{L}$. The CAM-B3LYP simulations lead to underestimation of the higher energy states $(\mathrm{H} \rightarrow \mathrm{L})$. A bathochromic shift in the spectra registered in DCM solution (Figure 1) is observed according to thin film spectra. Note that for the methyl substituted derivative DA-2 spectrum the H$1 \rightarrow \mathrm{L}$ is also red-shifted.

\section{Nonlinear optical properties}

\subsection{Theoretical nonlinear optical parameters}

The nonlinear optical (NLO) properties, such as Second Harmonic Generation (SHG) and Third Harmonic Generation (TGH) are affected by structural features. The properties such as the dipole moment $(\mu)$, polarizability $\left(\alpha_{i j}\right)$ [equivalent to $\chi^{1}(0)$ ] and the first hyperpolarizability $\left(\beta_{i j j}\right)$, [equivalent to $\left.\chi^{2}(0)\right]$, where $(i, j=x, y, z)$ are closely connected to nonlinear optical properties. These parameters were also calculated by DFT/B3LYP method. The obtained values for the most stable conformers and orientation of dipole moments vectors are collected in Table 3. The $\mu_{\mathrm{x}}, \mu_{\mathrm{y}}, \mu_{\mathrm{z}}, \mu_{\text {total }}$ values and orientation of dipole moments for less stable conformers are collected in Table 1S (Supporting information). We also report the isotropically averaged polarizabilities $(\langle\alpha\rangle)$, the polarizability anisotropies $(\Delta \alpha)$, and the isotropically first-order hyperpolarizabilities $\left(\beta_{v e c}\right)$, which are defined respectively, as [33]:

$\langle\alpha\rangle=\frac{1}{3}\left(\alpha_{x x}+\alpha_{y y}+\alpha_{z z}\right)$

$\Delta \alpha=\left\{\frac{1}{2}\left[\left(\alpha_{x x}-\alpha_{y y}\right)^{2}+\left(\alpha_{x x}-\alpha_{z z}\right)^{2}+\left(\alpha_{y y}-\alpha_{z z}\right)^{2}+6\left(\alpha_{x y}^{2}+\alpha_{x z}^{2}+\alpha_{y z}^{2}\right)\right]\right\}^{1 / 2}$,

$\beta_{\text {vec }}=\sqrt{\beta_{x}^{2}+\beta_{y}^{2}+\beta_{z}^{2}}$,

where $\beta_{i}(i=x, y, z)$ is given by $\beta_{i}=(1 / 3) \sum_{j=x, y, z}\left(\beta_{i j j}+\beta_{j i j}+\beta_{j j i}\right)$.

Calculated values in the Table 3 show that $\mu_{\text {tot }},\langle\alpha\rangle, \Delta \alpha$ for DA-1 and DA-2 are similar between themselves which results from the similarity in the structures of these molecules. The first-order hyperpolarizability $\left(\beta_{v e c}\right)$ being twice higher in the case of DA-2 suggests that DA-2 as compared to DA-1 can be more efficient in SHG.

Table 3. The calculated dipole moments, polarizabilities and hyperpolarizabilities for DA-1 and DA$2 \mathbf{t}-\mathbf{t}$ conformers. The orientation of dipole moment vectors are also shown. B3LYP/6-311(d,p)
DA-1 $t-t$
DA-2 $t$ - $t$ 


\begin{tabular}{|c|c|c|c|}
\hline Dipole moment [D] & $\mu_{\mathrm{x}}$ & 7.07 & 8.18 \\
\hline & $\mu_{\mathrm{y}}$ & 0.12 & 0.27 \\
\hline & $\mu_{z}$ & 0.53 & 1.10 \\
\hline & $\mu_{\text {tot }}$ & 7.09 & 8.26 \\
\hline Polarizability $\left[\AA^{3}\right]$ & $\alpha_{x x}$ & 165.1 & 174.1 \\
\hline & $\alpha_{\mathrm{xy}}$ & -7.7 & 10.0 \\
\hline & $\alpha_{y y}$ & 59.1 & 68.6 \\
\hline & $\alpha_{\mathrm{xz}}$ & 2.1 & 2.2 \\
\hline & $\alpha_{\mathrm{yz}}$ & -1.0 & 1.6 \\
\hline & $\alpha_{\mathrm{zz}}$ & 22.7 & 27.6 \\
\hline & $<\alpha>$ & 82.3 & 90.1 \\
\hline & $\Delta \alpha$ & 127.5 & 129.8 \\
\hline Hyperpolarizability & $\beta_{\mathrm{xxx}}$ & -10400.3 & -11636.1 \\
\hline$\left[\AA^{3}\right]$ & $\beta_{x x y}$ & -503.7 & -943.1 \\
\hline & $\beta_{x y y}$ & -19.1 & -31.3 \\
\hline & $\beta_{y y y}$ & 6.4 & 10.4 \\
\hline & $\beta_{\mathrm{xxz}}$ & 55.1 & 147.9 \\
\hline & $\beta_{\mathrm{xyz}}$ & 10.8 & 25.1 \\
\hline & $\beta_{\mathrm{yyz}}$ & 2.2 & 1.0 \\
\hline & $\beta_{\mathrm{xzz}}$ & 5.4 & 15.5 \\
\hline & $\beta_{\mathrm{yzz}}$ & 0.9 & 1.5 \\
\hline & $\beta_{\mathrm{zzz}}$ & 2.7 & 6.6 \\
\hline & $\beta_{\mathrm{vec}^{\mathrm{a}}}$ & 162.5 & 311.0 \\
\hline
\end{tabular}

${ }^{\mathrm{a}} \beta_{\text {vec }}$ is given in $10^{-53} \mathrm{C}^{3} \mathrm{~m}^{3} \mathrm{~J}^{-2}$

\subsection{Nonlinear optical measurements}

For the needs of further nonlinear optical measurements (harmonic generation and photoinduced birefringence) samples in the shape of thin polymeric films have been prepared. Typical guest-host system was used, where TTF-based dyads served as an active material. Poly(methyl metacrylate) which exhibits good optical properties, e.g. high transparency, low absorption coefficient in the investigated range and very efficient photostability, was used as the host matrix. Appropriate quantity 
of powders (commercially available PMMA and the dyads) was used. At the first stage the DA-1 and DA-2 materials were dissolved in DCM solvent and then mixed up in a proper ratio. The final ratio between each dyad and the polymer was $2 \%$ according to the dry mass (w/w). The final solution was used for thin films preparation using a drop casting technique. The resulting mixture was put on a clean silica glass plate and then left in a solvent atmosphere until the end of the solvent evaporation process. Thin films UV-Visible absorption spectra (Figure 5) of the two dyads (DA-1/PMMA and DA-2/PMMA) have been measured. Also in this figure proper laser modes have been marked where blue $(\lambda=405 \mathrm{~nm})$ and red $(\lambda=633 \mathrm{~nm})$ colored lines indicate pumping and reference beams, respectively, which were used in Optical Kerr Effect measurements. Grey $(\lambda=355 \mathrm{~nm})$ and green $(\lambda$ $=532 \mathrm{~nm}$ ) dotted lines indicate generated third and second harmonic of fundamental laser light, respectively. Samples thickness has been measured using profilometer (Tencor, ALFA-Step).

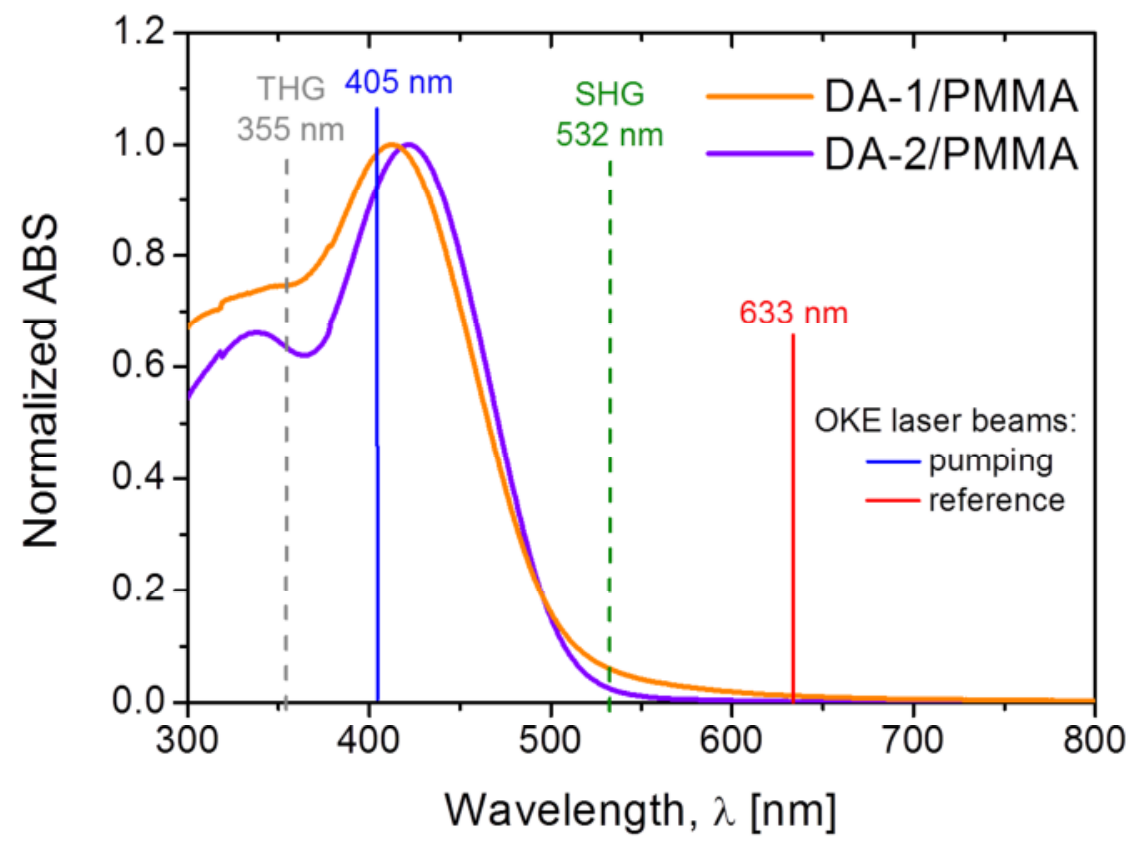

Figure 5. Absorption spectra from thin polymeric films of DA-1/PMMA and DA-2/PMMA. On the spectra proper laser lines were marked: $405 \mathrm{~nm}$ and $633 \mathrm{~nm}$ - pumping and reference laser beam from pump-probe OKE experiment; $355 \mathrm{~nm}$ and $532 \mathrm{~nm}$ - generated harmonics of laser light coming from the samples acquired in THG and SHG experiments.

\subsection{Harmonic generation}

As the example of the nonlinear optical process, where the energy in the shape of electromagnetic wave can be converted to light generation with doubled and tripled frequency are SHG and THG effects. In general, abovementioned phenomena can be used in various photonic 
applications mainly because of the fact that the incident laser beam (incident wavelength) can be converted as follows: $\omega \rightarrow 2 \omega$ or $\omega \rightarrow 3 \omega$ for SHG and THG, respectively. For the SHG phenomenon the active medium cannot be characterized by inversion symmetry meanwhile for the generation of light with tripled frequency (THG) none symmetry demands are needed to obtain the wave conversion. Such transformations of light have a variety of applications, i.e.: surface nonlinear optics, nonlinear optical microscopy or lasers constructions [34].

\section{Second and third harmonic generation}

In figure 7 (a) the typical Maker fringes of SHG in reference material are presented using the $s$ polarization mode of incident laser beam. As the reference material for this set of measurements a quartz slab was used. In Figure 6 (b) the SHG signals acquired for the investigated polymeric systems are shown. It is clearly visible that for DA-1 dyad the frequency doubling process is roughly four times more effective in comparison with the (DA-2/PMMA) system. It is also worth to point out that for the $p$ polarization mode of the incident beam in both cases the SHG signal is higher.
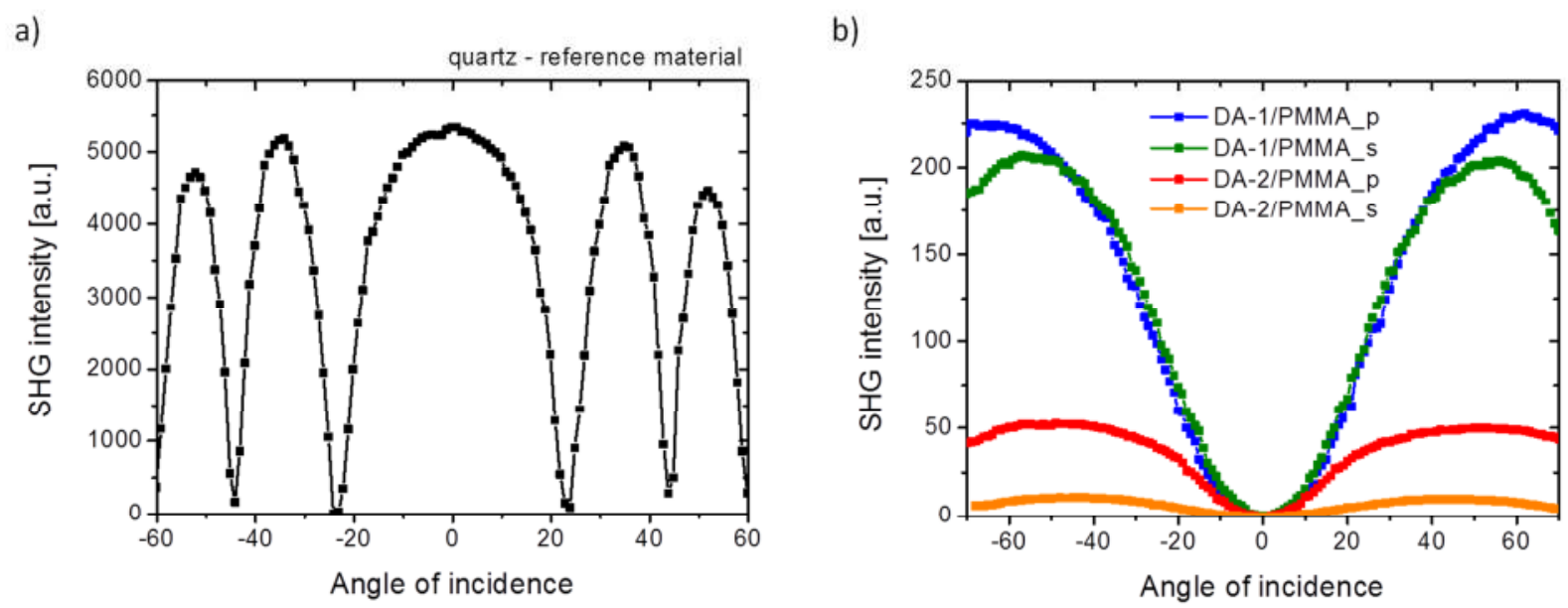

Figure 6. Maker fringes as the characteristic SHG signal coming from the quartz slab - reference material (a) and investigated molecular systems in both polarization modes of incident laser beam $-s$ and $p(b)$ as the function of rotation angle.

The second step of harmonic generation investigations were the THG measurements. In this case silica glass plate was used as the reference material. Basically, we have used the same experimental set-up with few technical modifications. In this case it was not necessary to pole the films, because THG effect belongs to the $3^{\text {rd }}$ order NLO phenomena, which does not require any symmetrical constraints. As it can be seen in Figure 7 (a), obtained THG Maker fringes of reference material are much more modulated than in the case of SHG measurements due to the less coherence length of 
silica in THG process. The two dyads DA-1 and DA-2 show THG efficiency about one order of magnitude less than silica (using $\chi^{(3)}$ as the comparable parameter).
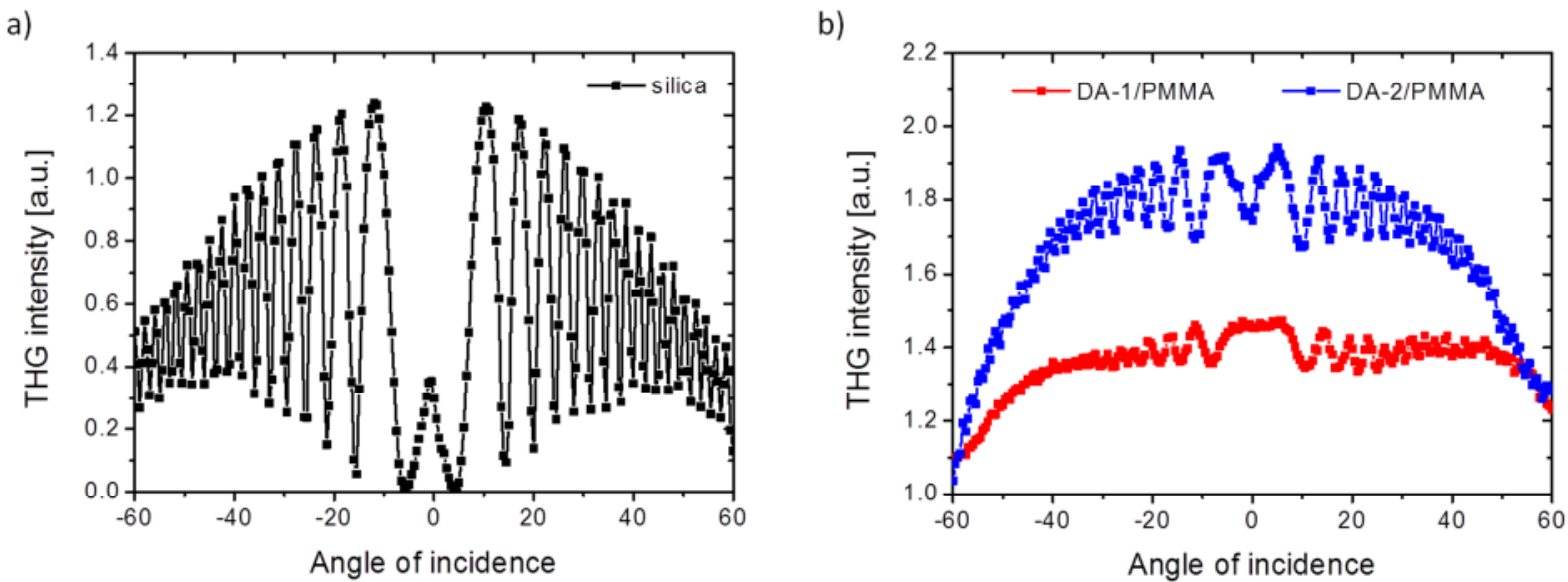

Figure 7. Maker fringes as the characteristic THG signal coming from quartz slab - reference material (a) and investigated molecular systems (b) as the function of rotation angle.

As the result of this step of NLO investigations the second and third order of nonlinear optical susceptibilities have been defined based on the theoretical models of Lee and Kubodera \& Kubayashi as described in reference [25], which allowed us to use abovementioned comparable methods for the characterization of our dyads (Table 4) [32]. It seems that differences in chemical structure have a significant impact on the $2^{\text {nd }}$ order NLO response while the opposite situation occurs in the case of THG. It is related to electron cloud distribution, which also has a great impact on molecular alignment realized by corona poling technique before SHG measurements. The positive inductive methyl groups present in DA-2/PMMA system affect the charge distribution (also during molecular alignment when high voltage was used), which finally can result in a lower second harmonic response of light generation. Much lighter and less significant than the methyl groups, hydrogen atoms (present in DA-1/PMMA system) do not affect so much the charge distribution in the whole structure, especially in the donor region, like in the previous case, which finally also do not change the efficiency of the TTF donating ability. Nevertheless, in this case molecular alignment can be more efficient and give as the result higher SHG signal. With respect to THG investigations the molecular alignment does not play such important role, therefore, it did not affect the final result of $\chi^{(3)}$ parameter and eventually gave very similar results for both investigated compounds (cf. Table 4) - the same order of magnitude for extracted values of $3^{\text {rd }}$ order NLO susceptibilitiy. It is worth to underline that the values of SHG and THG nonlinear optical parameters $\left(\chi^{(2)}\right.$ and $\left.\chi^{(3)}\right)$ describing the investigated systems are comparable with those of other organic systems (namely: functional polymers or polymers doped organic nonlinear chromophores). The values of the second and/or third 
order nonlinear optical susceptibilities are defined on the same or similar order of magnitude in comparison with i.e. azobenzene polymers [35], branched oligothienylenevinylenes derivatives [36], bisdithiafulvenyl-substituted tetrathiafulvalene [37] or polymer (in here: PMMA) doped pyrazoline derivatives [38]. It confirms the potential of the present materials in the field of harmonics of light generation.

Table 4. $2^{\text {nd }}$ and $3^{\text {rd }}$ order nonlinear optical susceptibilities of investigated materials estimated from SHG and THG experiments.

\begin{tabular}{|c|c|c|c|}
\hline Compound & $\begin{array}{c}\chi^{(2)}(\mathrm{s})^{\mathrm{a}, \mathrm{c}} \\
{[\mathrm{pm} / \mathrm{V}]}\end{array}$ & $\begin{array}{c}\chi^{(2)}(\mathrm{p})^{\mathrm{a}, \mathrm{c}} \\
{[\mathrm{pm} / \mathrm{V}]}\end{array}$ & $\begin{array}{c}\chi^{(3) \mathrm{b}, \mathrm{c}} \\
{\left[\mathrm{m}^{2} / \mathrm{V}^{2}\right]}\end{array}$ \\
\hline DA-1 & $\mathbf{6 . 8 0}$ & $\mathbf{8 . 0 0}$ & $3.75 \times 10^{-23}$ \\
\hline DA-2 & 0.94 & 2.72 & $2.04 \times 10^{-23}$ \\
\hline silica & --- & --- & $\mathbf{2 . 0 0} \times \mathbf{1 0}^{-\mathbf{2 2}}$ \\
\hline quartz & $\mathbf{1 . 0 0} \times \mathbf{1 0}^{-\mathbf{1 2}}$ & --- & -- \\
\hline
\end{tabular}

${ }^{\mathrm{a}}$ - calculated according to the used theoretical model, which takes into account the linear absorption coefficient

${ }^{\mathrm{b}}$ - calculated according to Lee model

${ }^{\mathrm{c}}$ - Maker fringes set-up employing the fundamental exit of a $30 \mathrm{ps} \mathrm{Nd}: \mathrm{YVO}_{4}$ laser with a repetition rate of $10 \mathrm{~Hz}$ at $1064 \mathrm{~nm}$; the energy per pulse was $40 \mu \mathrm{J}$.

\subsection{Optical Kerr Effect}

The results obtained above encouraged us to investigate the Optical Kerr Effect (OKE), which is a third order nonlinear optical effect. This is a typical pump-probe experiment, where two different laser lights are used. One of them (pumping one) has to be absorbed by the active material and the other one (the opposite) cannot be absorbed. This later is a reference beam, which transports the information to the photodiode (cf. Figure. 6.). In this experiment it is also possible to define $\chi^{(3)}$ parameter after proper analysis. Optical birefringence is induced inside the material by the second nonlinear refractive index. Therefore, photons which pass through the volume of such material go by two, perpendicular states of polarization and with different velocities, because these two refractive indices are not equal (anisotropy of refractive index is induced). Moreover, the main difference in comparison with SHG is that there are not any structural symmetry demands to cause and observe this effect in the material (like THG and any other $3^{\text {rd }}$ order NLO effects). Among material's characteristics based on the Optical Kerr Effect basically it is possible to distinguish two different 
aspects of investigations - dynamics of conformational transformations and photoinduced optical birefringence understood as the photoalignment of molecules in macro scale due to the Malus law (cf. typical OKE experimental set-up with crossed polarizer system) [39] OKE has a lot of various photonic applications, i.e.: all-optical switchers, optical memories and others [40-42]. Results, which describe dynamics of the conformational changes in one of the investigated materials (DA2/PMMA), which were acquired in AC mode on the oscilloscope are presented in Figure 8. As it can be seen in Figure 8 (a) conformational transformations are visible as the uprising and declining signal, which in fact shows transition between low-energy ground state (i.e. trans isomer) and highenergy molecular excited state (i.e. cis isomer), which is going to relax surplus of energy in various way. It can be typical thermal relaxation leading to obtain the minimum level of energy, which is present in this situation. According to the increasing values of chopper frequency light modulation, the amplitude of measured signal decay is shown in Figure 8 (b). Analogous correlations due to the dynamic conformational changes were done for DA-1 dyad (see supplementary information - Figure S1).

a)

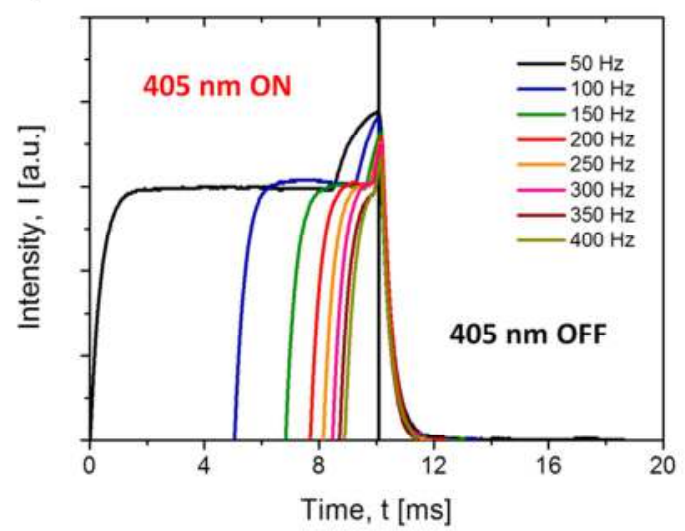

b)

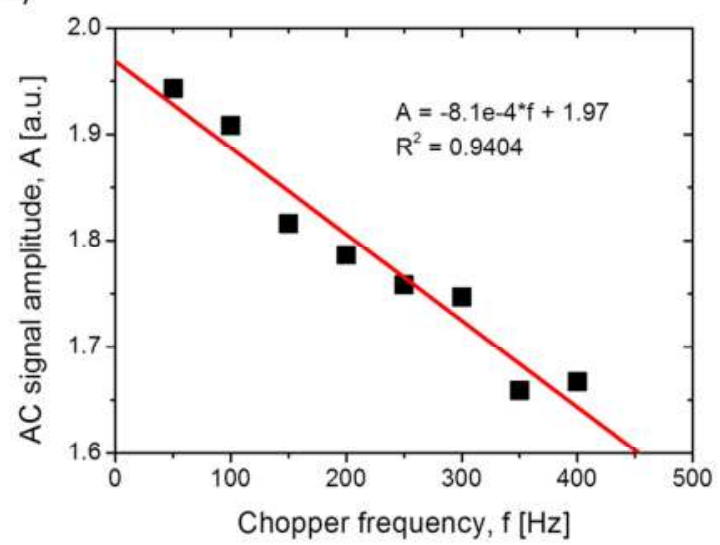

Figure 8. Dynamics of conformational changes (a), OKE AC signal amplitude in frequency function (b) for DA-2/PMMA system.

Using the same experimental set-up, but without chopper light modulations we have investigated photoinduced birefringence kinetics in the longer time basis (Figure 9). It allowed us to check the kinetics of the process of creating nonlinear optical refractive index, which causes anisotropy through the material (molecular alignment in the macro scale). After sample illumination by the pumping laser (405 $\mathrm{nm}$ ON in Figure 9 (a)) all of the active molecules which are not oriented in a perpendicular direction (long axis of the molecules) due to the polarization state of exciting laser light absorb the portion of photons $(h v)$. When the free volume is available, molecules are forced to change their molecular direction (due to the same long axis) for perpendicular orientation towards laser light. This behavior is visible on the graph as the signal's uprising. The opposite process 
(molecular reorientation according to their thermodynamics), which is achieved by the molecules and which is understood as low as possible energetically state, takes place during thermal relaxation in the dark exposition (signal decay). Based on this, the optical birefringence occurred and transformed reference laser light could go through the crossed polarizer system to the photodiode. Physics of this process (molecular ordering) is the same like with the dynamic changes of conformational states, but the difference that molecules can absorb the pumping laser light and locate themselves for a long time to obtain finally the best possible ordering due to the polarization state of excitation light. As the final effect of pump light illumination, we achieved complete anisotropic system. The uprising pumping beam intensity correlated with the photoinduced birefringence is shown in Figure 9 (b). It is linear function, which means that till the moment of sample degradation process due to the higher excitation intensity it is possible to enhance $\Delta n$ and obtain more effective and efficient system for alloptical switching. The same set of measurements performed for DA-1 compound is presented in supplementary information (Figure S2).

a)

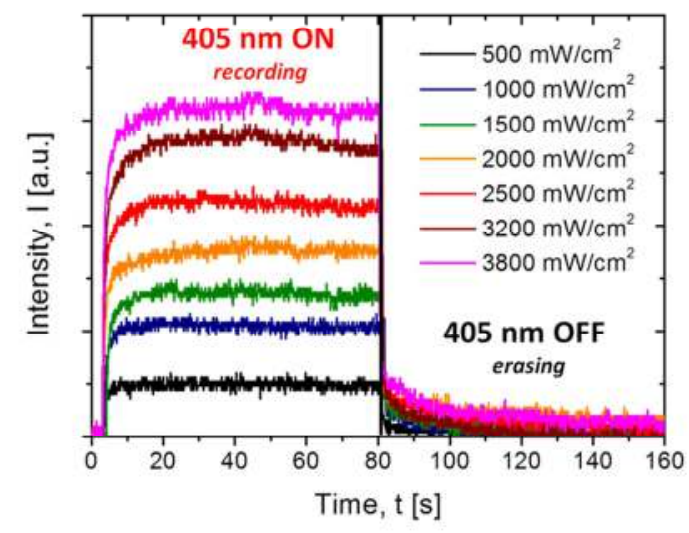

b)

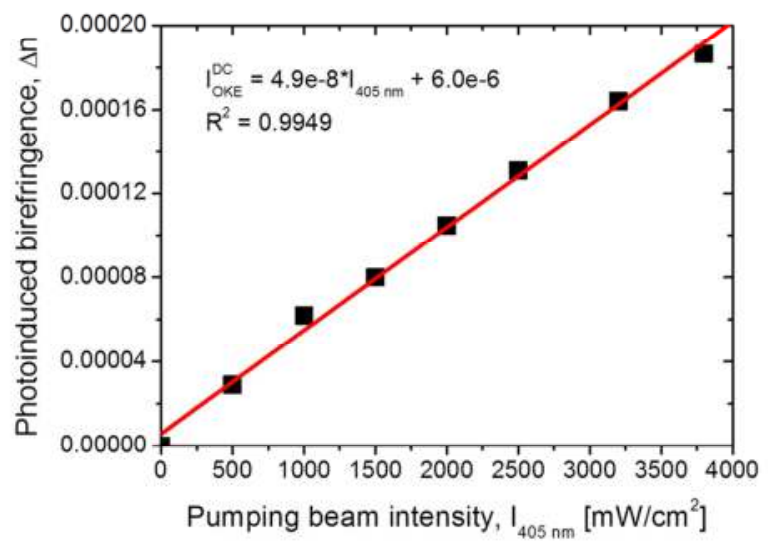

Figure 9. Photoinduced birefringence effect (a) as the function of pumping laser beam intensity (b) for DA-2/PMMA system.

In Table 5 we have gathered the most important parameters which were defined based on the Optical Kerr Effect experiments. The $3^{\text {rd }}$ order nonlinear optical susceptibility values and the second refractive index or Kerr constant are of the same order of magnitude for the two investigated dyads. In fact, both molecules exhibit similar chemical structure; therefore it can be assumed that such modifications do not determine different NLO response, which can change significantly physicochemical properties due to the OKE effect. Also the time constants for both dynamic changes of conformational states and photoinduced birefringence are very similar for the two investigated organic systems. It is worth noting that the time constant values (for dynamic mode measurements) 
are below half of the millisecond, which indicates that these materials can be used as ultrafast optical switchers, where the response time is a crucial parameter. However, time constant values determined for the long-term molecular ordering are higher than for the previous ones (their values are in the range of seconds regime) and it is typical for the guest-host systems, whereas the matrix branched polymer (in this case PMMA) is used [43]. The experimentally obtained values for the optical birefringence indicate that these kind of $\mathrm{D}-\pi$-A dyads could be valuable devices components. Moreover, the birefringence can be enhanced after an optimization process, since used excitation intensities did not cause any material's photodegradation changes. The Kerr constant defined for the investigated systems is a typical value for photo-switchable materials in solid states, which is in the order of magnitude equal to $10^{-6}-10^{-8}$.

Table 5. The $3^{\text {rd }}$ order nonlinear optical susceptibilities and other optical nonlinear parameters of the investigated materials estimated from the pump-probe OKE experiment.

\begin{tabular}{|c|c|c|}
\hline Compound & DA-1 & DA-2 \\
\hline$\chi^{(3)}\left[\mathrm{m}^{2} / \mathrm{V}^{2}\right]^{\mathrm{a}}$ & $4.0 \times 10^{-13}$ & $3.2 \times 10^{-13}$ \\
\hline $\mathbf{n}_{2}\left[\mathrm{~m}^{2} / \mathrm{W}\right]^{\mathrm{a}}$ & $5.0 \times 10^{-11}$ & $4.0 \times 10^{-11}$ \\
\hline$\chi^{(3)}[\mathrm{esu}]^{\mathrm{b}}$ & $3.4 \times 10^{-6}$ & $2.9 \times 10^{-6}$ \\
\hline$n_{2}\left[\mathrm{~cm}^{2} / \mathbf{W}\right]^{b}$ & $6.0 \times 10^{-8}$ & $5.0 \times 10^{-8}$ \\
\hline $\mathrm{B}\left[\mathrm{m} / \mathrm{V}^{2}\right]^{\mathrm{c}}$ & $5.1 \times 10^{-8}$ & $9.5 \times 10^{-8}$ \\
\hline$\Delta \mathbf{n}^{\mathbf{d}}$ & 0.00014 & 0.00013 \\
\hline $\mathbf{t}_{\text {grow }}[\mathrm{ms}]$ for $\mathrm{AC}$ mode & 0.34 & 0.34 \\
\hline $\mathbf{t}_{\text {decay }}[\mathrm{ms}]$ for $\mathrm{AC}$ mode & 0.35 & 0.33 \\
\hline $\mathbf{t}_{\text {grow }}[\mathrm{s}]$ for DC mode & 3.5 & 1.4 \\
\hline$t_{\text {decay }}[s]$ for DC mode & $1.3^{\mathrm{e}}$ & $1.3^{\mathrm{e}}$ \\
\hline
\end{tabular}
$\mathrm{mW} / \mathrm{cm}^{2} ;{ }^{\mathrm{e}}-$ low approximation level

\section{Conclusions}

We have prepared two TTF based D- $\pi$-A dyads using multistep synthetic procedure, where the bis(styryl)benzene system acts as an efficient conjugated $\pi$-bridge. The UV-Visible absorption spectroscopy as well as theoretical calculations indicate the occurrence of an intramolecular charge transfer (ICT) between the TTF donor and the nitrophenyl acceptor. According to the gathered 
experimental results characterizing nonlinear optical features of the two dyads one main point has to be stressed. The small structural changes, which were present in compounds DA-1 and DA-2 basically do not change physiochemical features in a significant meaning. By adding three extra methyl groups mainly in a donor part of the dyad DA-2 it caused very small difference due to the internal electron charge transfer. The effect is not measureable and observable according to the methods which were used for these organic systems. From the same reason the dynamics of photoisomerization process remained very similar for both cases. Small values of the time constants defining abovementioned changes indicate that these groups of materials exhibit a great potential of further exploration in the field of optical switchers construction, where the material's photoresponse time is a crucial parameter.

\section{Acknowledgements}

Laboratory (LIA, NAPOLI) is acknowledged for a partial financing support. A. S. would like to thank for financially support for dissertation preparation under ETIUDA II program which is financed by Polish National Science Centre (doctoral scholarship no. Dec-2014/12/T/ST4/00233). B. K. acknowledges the Pays de la Loire region for the financial support of research work in the framework of the "Molecular Systems for Nonlinear Optical Application" (MOSNOA) LUMOMAT project. A grant of computer time from the Wroclaw Center for Networking and Supercomputing (WCSS) is gratefully acknowledged.

\section{References}

[1] Brédas J-L., Beljonne D., Coropceanu V., Cornil J. Charge-Transfer and Energy-Transfer Processes in $\pi$ Conjugated Oligomers and Polymers: A Molecular Picture. Chem Rev 2004;104:4971-5004.

[2] Batail P. Introduction: molecular conductors. Chem Rev 2004;104:4887-90.Special issue on molecular conductors: Chem Rev 2004;104:4887-782.

[3] Martín N. Tetrathiafulvalene: the advent of organic metals. Chem Commun 2013; 49: 7025-27.

[4] Williams J.M., Ferraro J.R., Thorn R.J., Carlson K.D., Geiser U., Wang H.H., Kini A.M., Whangbo M.-H., Organic Superconductors (Including fullerenes), Synthesis, Structure, properties and Theory, Prentice Hall 1992.

[5] Bryce M. R., Murphy L.C., Organic metals Nature 1984;309:119-26.

[6] Canevet D., Sallé M., Zhang G.X., Zhang D.Q., Zhu D.B., Tetrathiafulvalene (TTF) derivatives: key buildingblocks for switchable processes. Chem Commun 2009:2245-69.

[7] Nielsen M.B., Lomholt C., Becher J., Tetrathiafulvalenes as building blocks in supramolecular chemistry II. Chem Soc Rev 2000;29:153-64.

[8] Segura J.L., Martin N., New Concepts in Tetrathiafulvalene Chemistry. Angew Chem Int Ed 2001;40:1372-409. 
[9] Yamada J., Sugimoto T., TTF Chemistry: Fundamentals \& Applications of Tetrathiafulvalene, Kodansha (Tokyo) and Springer (Berlin, Heidelberg, New York), 2004.

[10] Hardouin-Lerouge M., Hudhomme P., Sallé M. Molecular clips and tweezers hosting neutral guests. Chem Soc Rev 2011;40:30-43.

[11] McCall K.L., Morandeira A., Durrant J., Yellowlees L.J., Robertson N., Characterisation of a ruthenium bipyridyl dye showing a long-lived charge-separated state on $\mathrm{TiO}_{2}$ in the presence of $\mathrm{I}^{-} / \mathrm{I}_{3}{ }^{-}$. Dalton Trans 2010;39:4138-45.

[12] Wenger S., Bouit P.-A., Chen Q.L., Teuscher J., Censo D.D., Humphry-Baker R., Moser J.-E., Delgado J.L., Martín N., Zakeeruddin S.M., Grätzel M. Efficient Electron Transfer and Sensitizer Regeneration in Stable $\pi$ Extended Tetrathiafulvalene-Sensitized Solar Cells. J Am Chem Soc 2010;132:5164-69.

[13] de Lucas A.I., Martín N., Sánchez L., Seoane C., Andreu R., Garín J., Orduna J., Alcalá R., Villacampa B. The first tetrathiafulvalene derivatives exhibiting second-order NLO properties. Tetrahedron, 1998;54:4655-62.

[14] González M., Segura J.L., Seoane C., Martín N. Tetrathiafulvalene Derivatives as NLO-phores: Synthesis, Electrochemistry, Raman Spectroscopy, Theoretical Calculations, and NLO Properties of Novel TTF-Derived Donor- $\pi$-Acceptor Dyads. J Org Chem 2001;66:8872-82.

[15] Fuks-Janczarek I., Luc J., Sahraoui B., Dumur F., Hudhomme P., Berdowski J., Kityk I.V. Third-Order Nonlinear Optical Figure of Merits for Conjugated TTF-Quinone Molecules. J Phys Chem B 2005;109:10179-183.

[16] Sahraoui B., Fuks I., Bartkiewicz S., Matczyszyn K., Mysliwiec J., Kityk I.V., Berdowski J., Allard E., Cousseau J. Enhancement of third-order optical susceptibility of $\mathrm{C}_{60}$-TTF compounds using nematic liquid crystal. Chem Phys Letters 2002;365:327-32.

[17] Sahraoui B, Kityk I.V., Hudhomme P, Gorgues A. Temperature-pressure anomalies of electrooptic coefficients in C-60-TTF derivatives. J Phys Chem B 2001;105:6285-99.

[18] Iliopoulos K., Czaplicki R., El Ouazzani H., Balandier J.Y., Chas M., Goeb S., Sallé M., Gindre D., Sahraoui B. Physical origin of the third order nonlinear optical response of orthogonal pyrrolo-tetrathiafulvalene derivatives. Appl Phys Lett 2010;97:101104-06.

[19] Iliopoulos K, El-Ghayoury A, El Ouazzani H, Pranaitis M, Belhadj E, Ripaud E, Mazari M., Sallé M., Gindre D., Sahraoui B. Nonlinear absorption reversing between an electroactive ligand and its metal complexes. Opt Express 2012;20:25311-6.

[20] Iliopoulos K., Guezguez I., Kerasidou A. P., El-Ghayoury A., Branzea D., Nita G., Avarvari N., Belmabrouk H., Couris S., Sahraoui B. Effect of metal cation complexation on the nonlinear optical response of an electroactive bisiminopyridine ligand. Dyes and Pigments 2014;101: 229-233.

[21] Fabbrini G., Menna E., Maggini M., Canazza A., Marcolongo G., Meneghetti M.. Zinc-Induced Switching of the Nonlinear Optical Properties of a Functionalized Bis(styryl)benzene J Am Chem Soc 2004;126: 6238-39.

[22] Frisch, M. J.; Trucks, G. W.; Schlegel, H. B.; Scuseria, G. E.; Robb, M. A.; Cheeseman, J. R.; Montgomery Jr, J. A.; Vreven, T.; Kudin, K. N.; Burant, J. C.; Millam, J. M.; Iyengar, S. S.; Tomasi, J.; Barone, V.; Mennucci, B.; Cossi, M.; Scalmani, G.; Rega, N.; Petersson, G. A.; Nakatsuji, H.; Hada, M.; Ehara, M.; Toyota, K.; Fukuda, R.; Hasegawa, J.; Ishida, M.; Nakajima, T.; Honda, Y.; Kitao, O.; Nakai, H.; Klene, M.; Li, X.; Knox, J. E.; Hratchian, H. P.; Cross, J. B.; Adamo, C.; Jaramillo, J.; Gomperts, R.; Stratmann, R. E.; Yazyev, O.; Austin, A. J.; Cammi, R.; Pomelli, C.; Ochterski, J. W.; Ayala, P. Y.; Morokuma, K.; Voth, G. A.; Salvador, P.; Dannenberg, J. J.; Zakrzewski, V. G.; Dapprich, S.; Daniels, A. D.; Strain, M. C.; Farkas, O.; Malick, D. K.; Rabuck, A. D.; 
Raghavachari, K.; Foresman, J. B.; Ortiz, J. V.; Cui, Q.; Baboul, A. G.; Clifford, S.; Cioslowski, J.; Stefanov, B. B.; Liu, G.; Liashenko, A.; Piskorz, P.; Komaromi, I.; Martin, R. L.; Fox, D. J.; Keith, T.; Al-Laham, M. A.; Peng, C. Y.; Nanayakkara, A.; Challacombe, M.; Gill, P. M. W.; Johnson, B.; Chen, W.; Wong, M. W., Gonzalez, C.; Pople, J. A. Gaussian 09, Revision D.01, Gaussian Inc., Wallingford CT, 2009.

[23] Tomasi J., Mennucci B., Cammi R., Quantum Mechanical Continuum Solvation Models. Chem Rev 2005;105: 2999-3094.

[24] Miertus S., Scrocco E., Tomasi J. Electrostatic interaction of a solute with a continuum. A direct utilizaion of AB initio molecular potentials for the prevision of solvent effects. Chem Phys 1981;55:117-29.

[25] Sahraoui B., Luc J., Meghea A., Czaplicki R., Fillaut J.-L., Migalska-Zalas A. Nonlinear optics and surface relief gratings in alkynyl-ruthenium complexes. J Opt A: Pure Appl Opt 2009;11:024005-26.

[26] Witiak D.T., Loper J.T., Ananthan S., Almerico A.M., Verhoef V.L., Filppi J.A., Mono and bis(bioreductive) alkylating agents: synthesis and antitumor activities in a B16 melanoma model. J Med Chem 1989;32:1636-42.

[27] Garin J., Orduna J., Uriel S., Moore A.J., Bryce M.R., Wengener S., Yufit D.S., Howard J.A.K. Improved Syntheses of Carboxytetrathiafulvalene, Formyltetrathiafulvalene and (Hydroxymethyl)tetrathiafulvalene:Versatile Building Blocks for New Functionalised Tetrathiafulvalene Derivatives. Synthesis 1993;489-93.

[28] Moore A.J., Bryce M.R., Batsanov A.S., Cole J. C., Howard J.A.K. Functionalised Trimethyltetrathiafulvalene (TriMe-TTF) Derivatives via Reactions of Trimethyltetrathiafulvalenyllithium with Electrophiles: X-ray Crystal Structures of Benzoyl-TriMe-TTF and Benzoylthio-TriMe-TTF. Synthesis 1995;6:675-82.

[29] Park Y.I., Kuo C.-Y., Martinez J.S., Park Y.-S., Postupna O., Zhugayevych A., Kim S., Park J., Tretiak S., Wang H.-L. Tailored Electronic Structure and Optical Properties of Conjugated Systems through Aggregates and Dipole-Dipole Interactions. Appl Mater Interfaces 2013;5: 4685-95.

[30] Scalmani G., Frisch M.J., Mennucci B., Tomasi J., Cammi R., Barone V. Geometries and properties of excited states in the gas phase and in solution: theory and application of a time-dependent density functional theory polarizable continuum model. J Chem Phys 2006;124: 094107:1-15.

[31] Yanai T., Tew D.P., Handy N.C. A new hybrid exchange-correlation functional using the Coulomb-attenuating method (CAM-B3LYP). Chem Phys Chem 2004;393:51-7.

[32] Ayadi A., Branzea D.G., Benmensour M., Boucekkine A., Zouari N., El-Ghayoury A. Azo-based iminopyridine ligands: synthesis, optical properties, theoretical calculations and complexation studies. Tetrahedron 2015;71:7911-19.

[33] Alparone A. Static and Dynamic Electronic (Hyper)polarizabilities of Dimethylnaphthalene Isomers: Characterization of Spatial Contributions by Density Analysis. Scientific World Journal. 2013;2013: 832682

[34] Nonlinear Optics 3rd Edition, Robert W. Boyd. Print Book ISBN: 9780123694706; eBook ISBN: 9780080485966. Publisher: Academic Press @2008.

[35] El Ouazzani H., Iliopoulos K., Pranaitis M., Krupka O., Smokal V., Kolendo K., Sahraoui B. Second- and Third-Order Nonlinearities of Novel Push-Pull Azobenzene Polymers. J Phys Chem B 2011;115:1944-49.

[36] Fuks-Janczarek I., Nunzi J-M., Sahraoui B., Kityk I.V., Berdowski J., Caminade A.M., Majoral J.-P., Martineau A.C., Frere P., Roncali J. Third-order nonlinear optical properties and two-photon absorption in branched oligothienylenevinylenes. Opt Commun 2002;4-6:461-66.

[37] Sahraoui B., Rivoire G., Terkia-Derdra N., Sallé M., Zaremba J. Third-order nonlinear optical properties of new bisdithiafulvenyl-substituted tetrathiafulvalene. J Opt Soc Am B 1998 ;15:923-28. 
[38] Papagiannouli I., Szukalski A., Iliopoulos K., Mysliwiec J., Couris S., Sahraoui B. Pyrazoline derivatives with a tailored third order nonlinear optical response. Rsc Adv 2015;5: 48363-67.

[39] Szukalski A., Haupa K., Miniewicz A., Mysliwiec J. Photoinduced Birefringence in PMMA Polymer Doped with Photoisomerizable Pyrazoline Derivative. J Phys Chem C 2015;119:10007 Scientific World Journal. 2013;2013: 83268-14

[40] Wu S.Z., Lu M., She W.L., Yan K., Huang Z.Z. All-optical switching effect in PVK-based optoelectronic composites. Mater Chem Phys 2004;83:29-33.

[41] Delaire J.A., Nakatani K. Linear and nonlinear properties of photochromic molecules and materials. Chem Rev 2000;100:1817-45.

[42] Okamoto T., Kamiyama T., Yamaguchi I. All-optical spatial light modulator with surface plasmon resonance. Opt Lett 1993;18:1570-72.

[43] Pawlik G., Mitus A.C., Mysliwiec J., Miniewicz A., Grote J.G. Photochromic dye semi-intercalation into DNAbased polymeric matrix: Computer modeling and experiment. Chem Phys Lett 2010;484:321-23. 
- Two TTF based donor-pi-acceptor dyads have been synthesized

. Occurrence of an intramolecular charge transfer (ICT) band between the donor and acceptor fragments

- High NLO response has been found for the two dyads

- The experimental finding have been verified by theoretical calculations 